\title{
Trade Credit: Suppliers as Debt Collectors and Insurance Providers
}

\author{
Vicente Cuñat ${ }^{1}$ \\ Universitat Pompeu Fabra \\ $\&$ \\ Financial Markets Group (LSE)
}

13th February 2004

${ }^{1}$ I would like to thank Nobu Kiyotaki for his encouragement and advice. I have also benefited from the helpful comments of Heski Bar-Isaac, Andrea Caggese, Guillermo Caruana, Andrew Ellul, Antoine Faure-Grimaud, Leonardo Felli, Maria Guadalupe, François OrtaloMagné, John Moore, Steve Pischke, Javier Suárez and Elena Zoido. All remaining errors are my sole responsibility. Correspondence to: Universitat Pompeu Fabra, C/ Ramon Trias Fargas 25-27, Barcelona 08005 Spain. e-mail vicente.cunat@econ.upf.es 


\begin{abstract}
There are two fundamental puzzles about trade credit: why does it appear to be so expensive, and why do input suppliers engage in the business of lending money? This paper addresses and answers both questions analysing the interaction between the financial and the industrial aspects of the supplier-customer relationship. It examines how, in a context of limited enforceability of contracts, suppliers may have a comparative advantage over banks in lending to their customers because they hold the extra threat of stopping the supply of intermediate goods. Suppliers may also act as lenders of last resort, providing insurance against liquidity shocks that may endanger the survival of their customers. The relatively high implicit interest rates of trade credit result from the existence of default and insurance premia. The implications of the model are examined empirically using parametric and nonparametric techniques on a panel of UK firms.
\end{abstract}

Keywords: Trade Credit, Debt Enforceability, Liquidity (JEL G30, M130, D920) 


\section{Introduction}

Trade credit arises when a supplier allows a customer to delay the payment of goods already delivered. It is generally associated with the purchase of intermediate goods. Empirical evidence shows that the implicit interest rate in a trade credit agreement is generally very high compared to the rates of bank credit. In spite of this apparent high cost, trade credit is widely used and represents an important proportion of firms' finance. It is therefore surprising that banks do not take over this potentially profitable business, offering more credit lines to finance commercial transactions. This paper addresses the following questions at the heart of the trade credit puzzle: i) Why is trade credit so expensive? and ii) Why is trade financed by suppliers instead of banks?

In our model a financial relationship between a supplier and a customer emerges as a natural consequence of their commercial interaction, despite the existence of a competitive banking sector. This is based on two basic elements. On the one hand, suppliers are able to enforce debt repayment better than banks, as they hold the threat of stopping the supply of intermediate goods to their customers. On the other hand suppliers may act as liquidity providers, supporting their customers whenever they experience temporary liquidity shocks. The necessary condition for these elements to exist is the existence of a surplus that will be split between suppliers and customers if they stay together. In other words, there must be a link between the supplier and the customer that makes it costly for the customer to find alternative suppliers and makes it costly for the supplier to loose its current customers. As a result, the high interest rate of trade credit, is justified by the existence of a default premium and an insurance premium. The default premium accounts for the fact that, in our model, suppliers lend when banks are not willing to lend. They use their extra enforceability power to lend on the basis of returns that are non-verifiable and stochastic. This makes trade credit more risky than bank debt. The insurance premium is related to the fact that suppliers foresee the future needs of liquidity of their customers. As they know that they may have to bail out customers in need of extra liquidity, they will charge them a premium for providing insurance against potential liquidity shocks.

The reason why trade credit appears to be an expensive form of finance lies within the structure of a standard trade credit contract. A typical deal normally involves three elements: a discount on the price agreed if the buyer pays early; the number of days that qualify for early payment; and the maximum number of days for payment. For example, a common contract called "2-10 net 30" means that if customers pay within ten days 
of delivery they qualify for a $2 \%$ discount. Otherwise they can pay up to 30 days after delivery. The discount for early payment implies an interest rate that the customer pays for the credit received. In the case of the "2-10 net 30" contract, the customer is effectively receiving credit at a $2 \%$ rate for 20 days. Thus the equivalent one year interest rate of this deal is about $44 \%$. This is an extremely high rate compared with the market rate that a bank would charge for a similar type of loan. Other common deals also have very high interest rates. ${ }^{1}$ Despite this high cost, trade credit still constitutes a considerable share of firms' finance. For example, trade credit accounts for roughly one fifth of the total assets of a representative firm and about one half of the short-term debt in two different samples of medium sized UK firms and small sized US firms, as shown in Table $1 .^{2}$

\section{Table 1}

Relative Size of Trade Credit

(Average Over Firms)

\begin{tabular}{|l|l|c|c|c|}
\multicolumn{1}{l}{ Country } & Dataset & Trade Credit/Assets & Trade Credit/Debt & Trade Credit/ST Debt \\
\hline \hline UK & FAME & $17 \%$ & $43 \%$ & $52 \%$ \\
US & NSSB & $18 \%$ & $34 \%$ & $58 \%$ \\
\hline \hline
\end{tabular}

Furthermore, these levels are higher in periods when buyers face temporary liquidity shocks. Suppliers seem to lend to their customers experiencing financial trouble, even when banks are not willing to lend. This additional lending may occur through financing a higher proportion of purchased goods or by extending the agreed maturity of the loans. Furthermore, in many circumstaces, this extra lending occurs via late payment of already extended debts. For example, in the NSSB sample $59 \%$ of the firms declared that they had made some payments after the due date during the last year. These late payments do not usually carry a penalty for the customers.

The role of suppliers as debt collectors is in line with the fact that trade credit tends to be higher in small, young and high growth firms that are the ones with higher difficulties in accessing other forms of finance. ${ }^{3}$ However, in the empirical part of the

\footnotetext{
${ }^{1} \mathrm{Ng}$ et al (1999) find that "2-10 net 30" is the most common deal in a sample of US firms. Other common deals such as "8-30 net 50" imply even higher implicit interest rates. In this case the annual implied interest rate is $358 \%$

${ }^{2}$ FAME (Financial Analysis Made Easy) is a database of medium-sized UK firms from 1993 until 1999 (see Section 5.1), while NSSB (National Survey of Small Busines) is a 1993 sample of 3000 small US firms.

${ }^{3}$ See Nilsen (1994) (1999), Elliehausen and Wolken (1993), Berger and Udell (1998).
} 
paper, we find that the relationship between the age of a firm and the levels of trade credit used is non-linear. New-born firms start with low levels of trade credit but it builds up very quickly in the early years of a firm's life. This reinforces our hypothesis that trade credit is related to the existence of a link between suppliers and customers. If this link takes time to build up, trade credit should also grow as the relationship evolves.

The results of the model are consistent with the existing stylised facts, in particular with the high implicit interest rates and the extensive use of trade credit. Furthermore, in Section 5 we test some of the empirical implications of the model, finding support for the existence of a link between suppliers and customers that takes time to bulid and for the help of suppliers to their customers that experience temporary problems.

This is a new explanation for the characteristics of trade credit that is, to some extent, complementary to the ones of previous articles. ${ }^{4}$ For example, trade credit can be seen like in Ferris (1981) as a means of payment to reduce transaction costs when the timing of the arrival of new supplies is uncertain. This is consistent with the existence of a free delayed payment period like the first ten days in the "2-10 net 30" deal of the above example. However, the model remains silent about why trade credit is so expensive and why firms are willing to pay such cost. For example in the NSSB sample $46.4 \%$ of the firms forgo the discount for early payment in at least half of their purchases. Other literature considers trade credit as a financial instrument. Biais and Gollier (1997) provide an explanation for trade credit based on the existence of some form of asymmetric information; Brennan, Maksimovic and Zechner (1988) highlight the possibilities that trade credit offers for price discrimination; ${ }^{5}$ and there is a new stream of literature that focuses on the role of trade credit in liquidation, default or renegotiation. Among the latter, Frank and Maksimovic (1999) explain the existence of trade credit as a result of suppliers having an advantage in liquidating intermediate goods in case of default by their buyers. ${ }^{6}$ On the other hand Wilner (2000) assumes that suppliers incur sunk

\footnotetext{
${ }^{4}$ For an extensive review of theoretical and empirical literature on Trade Credit see Mian and Smith (1992), Petersen and Rajan (1997) and Smith (1995). There are also articles that base the existence of trade credit on tax advantages as Brick and Fung (1984). See also Emery (1984) and Schwartz (1974) for models in which suppliers have superior access to financial markets.

${ }^{5}$ Brennan, Maksimovic and Zechner (1988) and Smith (1987) link the asymmetric information and the price discrimination literature by showing that suppliers can use credit terms to screen their customers in the presence of asymmetric information. The idea of price discrimination through trade credit stresses the fact that from an economist's point of view it is sometimes impossible to differentiate between prices paid for intermediate goods and interest rates. The nature of a seller-buyer relationship is both financial and commercial and these two aspects can not be easily disentangled.

${ }^{6}$ This advantage comes from the fact that suppliers can claim back supplied intermediate goods in
} 
costs that are specific to their buyers, so in the case of renegotiation of debts, they give more concessions to customers than banks. Both models conclude that suppliers will specialise in financing buyers with low creditworthiness, for whom liquidation is more likely to occur. High interest rates associated with trade credit reflect the fact that low quality firms are self-selected towards being financed by their suppliers.

Our model differs from those in the existing literature in various aspects. In the first place, we justify the existence of trade credit on the basis of suppliers being able to enforce debt repayment better than banks. This extra enforceability power comes from the existence of a link that makes both suppliers and customers costly to substitute. In the model this link takes the form of intermediate goods being specific to the buyer. Secondly, the existence of this link also justifies the fact that suppliers will help customers in trouble because they are costly to substitute. This help is not just restricted to renegotiation in case of default, but is more of an insurance against liquidity shocks that the customer may face. We model this an explicit bail-out in the form of extra funds or extra goods delivered on credit, but it can also be seen as extra flexibility in the terms of payment. The final difference is that, in equilibrium, all firms use both trade credit and bank credit, even if we assume that banks are relatively more competitive lenders than suppliers. Suppliers can issue trade credit when their customers have already borrowed from banks up to the point where banks are not willing to lend any more funds. ${ }^{7}$

We also test empirically some of the implications of the model with an extensive pannel of UK firms applying standard panel data techniques and also non-parametric methods. This empirical evidence shows how trade credit trends to be higher the higher the link between suppliers and customers, also relating measures of firm performance to trade credit we find evidence of the support given by suppliers to their customers when they experience small problems. Finally the evolution of trade credit with respect to

case of default and have the distribution channels to re-sell them, if they are not too buyer specific. The ability to repossess these commodities will be more or less important depending on the average length of stay of non processed goods in the customer's firm compared with the maturity of trade credit. Note that while our model predicts higher levels of trade credit when inputs are buyer specific, Frank and Maksimovic (1999) predict the opposite relationship.

${ }^{7}$ So far, only Biais and Gollier (1997) and Frank and Maksimovic (1999) had an equilibrium result where bank and trade credit were mixed optimally. According to Biais and Gollier, customers choose the right proportion of trade credit vs bank credit to commit credibly to avoid collusion with their suppliers. In Frank and Maksimovic low quality buyers get only trade credit while high quality buyers get mixed finance. Both models rely on the existence of a single monopolistic financier. Our model proposes an alternative explanation for this mix, based on the verifiablility of the returns of the customer. The results of section 5.4 support our hypothesis, showing a high sensitivity of this mix with respect to the levels of collateral of the firm. 
collateral levels and liquidity also seems to support the implications of our theoretical model.

The structure of the paper is as follows: in Section 2 we explain the model; in Section 3 the question of suppliers as insurance providers is explored in more depth, comparing supplier insurance with alternative forms of insurance; in Section 4 we calculate the implicit interest rates of trade credit; in Section 5 the empirical implications of the model are explored and Section 6 concludes.

\section{The Model}

The model explains the existence of trade credit as a natural result between firms that are tied by commercial or technological links, in a context where debt repayment may be difficult to enforce.

The idea behind this paper is that a supplier and a customer are more productive the longer they stay together. In other words, there are sunk costs, learning-by-doing processes, tailor-made products and so on that link suppliers and customers in a way that makes it costly for them to switch to another partner. The extra profits of staying together will normally be split according to the bargaining power of the agents, generating an interior division of this surplus. Because the customer gets part of this extra surplus, the supplier may be more efficient than banks in enforcing debt repayment having the additional threat of stopping the supply of intermediate goods in case of default by the customer. ${ }^{8}$ On the other hand, given that the supplier also gets part of this extra surplus, she will act as lender of last resort if the customer experiences temporary liquidity needs.

The high interest payments associated with trade credit can then be justified by two extra premia on top of the market interest rate. In the first place there is a premium that suppliers get for providing credit when banks are not willing to lend. We call this premium the default premium. Secondly suppliers will also demand an insurance premium, due to the fact that they may be asked to provide extra liquidity in the future.

The aim of the model is not only to give an explanation for the existence and high cost of trade credit, but also to provide testable implications that can support or reject our hypotheses. Some of the features of the model, like having an explicit startup stage

\footnotetext{
${ }^{8}$ In our model, like in Kiyotaki and Moore (1997) Hart and Moore (1994) (1998) and Hart (1995), debt contracts can not be enforced in themselves, so it is necessary that the lender has some external threat in order to generate some kind of lending. Bolton and Scharfstein (1990) suggest that the threat of not refinancing is what allows debtors to effectively claim back debts.
} 
or liquidity shocks that are correlated with the performance of the firm, bring some complexity to the model that may seem unnecessary from a purely theoretical point of view but are in place to bring the model closer to the empirical evidence of section 5 .

In this section, we begin by describing the different agents involved in the model. Throughout the article, and for the sake of clarity, we will refer to the supplier as "she" and the customer as "he". Secondly, we proceed to explain the production technology of the customers, with special attention given to the existence of a link between suppliers and customers. Then we describe the bargaining between the agents and the structure of cash flows implied by this bargaining. Next we conjecture a certain equilibrium structure and see that, under certain conditions this, is the only equilibrium of the model. Finally we find the equilibrium values of the different endogenous parameters of the model.

\subsection{Agents}

The model is in discrete time with infinite periods. All agents live forever, are risk neutral and maximise future discounted profits. There are three types of agents in the model: banks, suppliers and customers. Banks are deep pockets, having access to unlimited funds. They discount future cash flows with a factor $\beta<1$. This implies that banks are willing lend or borrow at a market interest rate $i$ such that $\beta \equiv \frac{1}{1+i}$. Suppliers are also deep pockets with the same discount factor $\beta$; they are therefore also willing to lend or borrow at the same rate of banks. They also provide their customers with the necessary intermediate goods necessary for production. These goods are produced with a technology with constant returns to scale, we normalise the cost to produce each unit of intermediate goods to one. These inputs may be of two kinds; generic goods which can be provided by any supplier and serve any customer; or specific goods, which have been tailored to the needs of a single customer and can only be provided by a particular supplier. Finally, customers are endowed with a limited amount of wealth $w$; they are also relatively impatient with respect to deep pockets, having a discount factor $\delta<\beta$. Each customer can only run one business at a time. Every period, the customer buys a variable amount $I$ of intermediate goods delivered by a single supplier. By transforming these inputs, the customer obtains some net income at the end of the period that can either be $A_{h} I$ or $A_{l} I$ where $A_{h}>A_{l}$. These returns are stochastic, and the probability of obtaining a high or a low return depends on whether the production process uses a startup technology with low expected productivity that transforms generic inputs; or a mature technology with high expected productivity that transforms specific inputs.

Assumption 1: Suppliers are more abundant than customers. 
So in the absence of any link between suppliers and customers, customers can costlessly search for a supplier that sells them inputs at cost value.

\subsection{Technology}

The possibility of using either type of technology is determined by the process shown in Figure 1:

Figure 1

Production Technologies

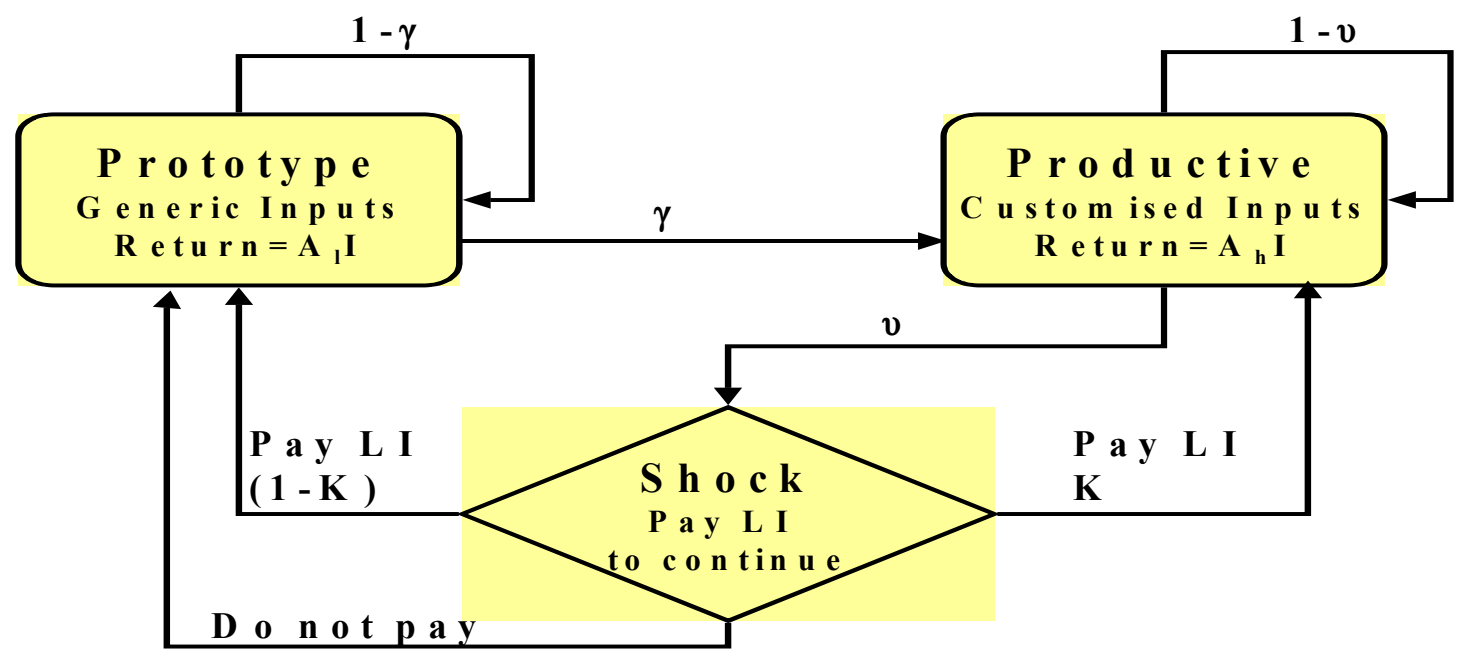

Initially when a supplier and a customer meet for the very first time they must work with the technology that uses generic inputs. This represents a startup stage where the customer tries different ideas until finding a successful one. With a probability $(1-\gamma)$ the idea is unsuccessful, so the customer receives a return of $A_{l} I$ and remains in the startup stage for the next period. However with some small probability $\gamma$ the idea is successful. A successful idea gives the customer returns of $A_{h} I$ and allows them to use a more productive technology that uses specific inputs in the next period. We call this technology specific or also mature technology. When the customer uses this mature technology there is a probability $(1-v)>\gamma$ that the project is successful without any further payment, so the customer gets returns of $A_{h} I$ and can use the mature technology again in the next period. However, with a probability $v$ the customer may experience a liquidity shock. The liquidity shock represents any kind of problem that the firm may experience that requires an additional disbursement of money to continue producing. The structure of this liquidity shock is the following: The cost of the shock is LI. If the firm invests $L I$ in solving "the problem" then with probability $k$ the process will be successful, and with probability $(1-k)$ the project will be unsuccessful. However if 
the firm decides not to invest this sum, the project is sure to be unsuccessful. Again a successful project entails returns equal to $A_{h} I$ and the possibility to keep using the mature technology while an unsuccessful project means going back to the startup stage with returns equal to $A_{l} I .^{9}$

A good example of what we mean by this liquidity shock is the existence of a breakdown in the production process that costs $L I$ to repair. If the firm does not repair the breakdown the project is definitely unsuccessful, while if the breakdown is repaired the project is successful with probability $k$. We can also see this liquidity shock as a delay in production. At the end of the period, the customer has to decide wether to get an unsuccessful return or wait some more time $t$ to get a succesful return with probability $k$. Therefore we can see $L I$ as the time value of delaying returns for time $t$.

There is one important characteristic of the mature technology, that is crucial for the understanding of the model. When the customer has already been successful in the startup stage and is about to use the specific technology for the first time, he has to choose which supplier is going to be the one that will produce the necessary inputs. The customer faces a competitive market of suppliers willing to be the chosen one to produce these tailor-made inputs. From then onwards, at any point in time, a customer or a supplier can resolve their relationship and switch to another partner. However, given that the inputs are specific, after switching they must start using the generic technology again. The supplier owns the blueprint or the knowledge to produce the customised inputs that are necessary in the mature technology.

So a customer can lose the advantages of a specific inputs technology, either because there has been an unsuccessful period or by switching to a different supplier.

Assumption 2: $L<K\left(A_{h}-A_{l}\right)$

So it is always profitable for the customer to pay the liquidity shock if she has sufficient funds. It is convenient to define $\alpha=v k+(1-v)$ as the ex ante success probability, conditional on always paying the liquidity shock. We are restricting ourselves to parametrisations that make it optimal to pay the liquidity shock; therefore, conditional on always paying the liquidity shock, the choice of technology can be summarised by a Markov process with transition probabilities $\gamma$ and $\alpha$, as shown in Figure $2 .{ }^{10}$

\footnotetext{
${ }^{9}$ The liquidity shock is modelled in a similar fashion to Holmstrőm and Tirole (1998). From a theoretical point of view the shock need not be correlated with the probability of success of the project. However, as we will see, this slightly more complex model is more realistic when it comes to empirical estimation.

${ }^{10}$ The shock probability $v$ is correlated with the success probability $\alpha$, so even though the choice of the production technology is a Markov process, the whole setup is not.
} 
Figure 2

Transition probabilities conditional on always paying the liquidity shock

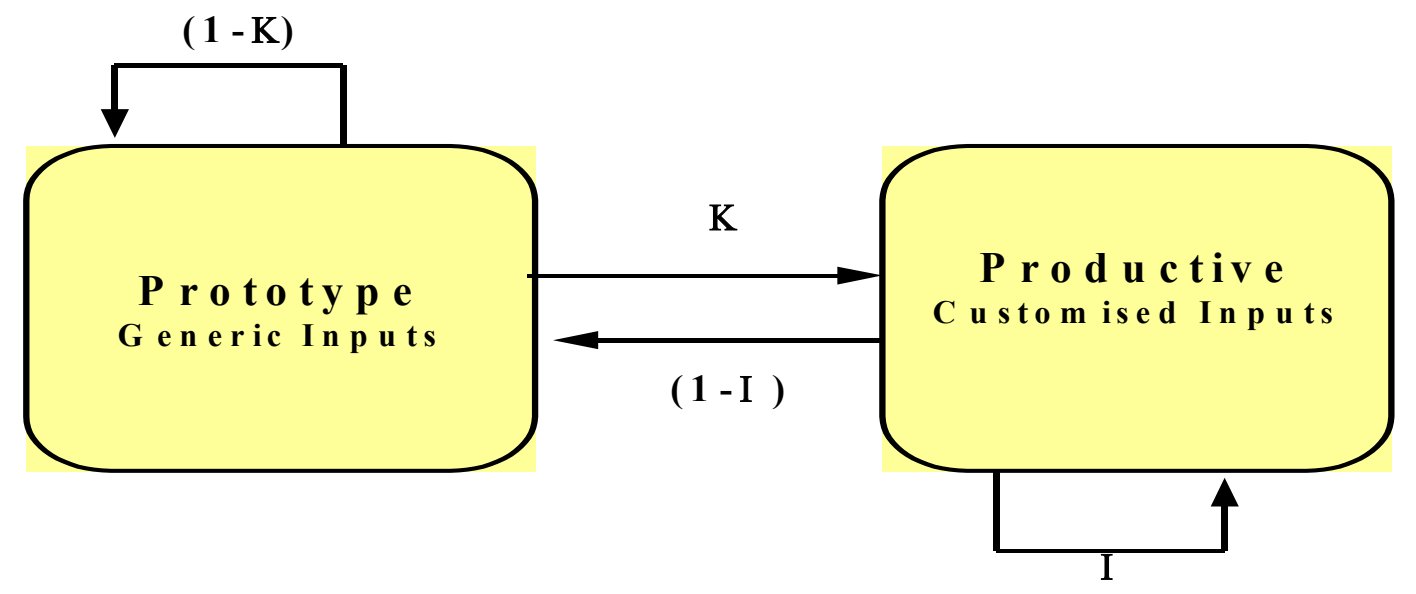

Assumption 3: Structure of returns.

A proportion of investment $c I$ is consumed by the customer during the production process. ${ }^{11}$ Also a proportion $\theta I$ of the value of the firm can be used as collateral to secure debt repayment. The remainder of returns are not verifiable and can not be collateralised. By not verifiable, we mean that it is not possible to write a contract that implies some commitment of these future returns. This precludes in particular the writing of a standard debt contract. It is useful to redefine these remaining returns as follows.

$$
\begin{aligned}
A_{h} I & =c I+\theta I+R I \\
A_{l} I & =c I+\theta I+r I
\end{aligned}
$$

Thus $R I$ and $r I$ represent the part of the returns of the customer that can be freely used but is genuinely non verifiable, as the rest of the returns can either be backed by collateral, or must be consumed.

Assumption 4: $\beta(\theta+\alpha R+(1-\alpha) r-v L)<1$

The expected discounted returns of the firm, excluding the ones that must be consumed, do not cover investment costs, not even when the technology is specific and we use the discount factor $\beta$. This assumption implies that infinite investment is not possible, not even if the customers could somehow commit the non-collateralisable part of

\footnotetext{
${ }^{11}$ The existence of $c I$ rules out the infinite postponement of consumption and can be seen as private benefits that the entrepreneur enjoys while producing, or wages, or as a minimum level of dividends.
} 
their returns. ${ }^{12}$ We do not discount the proportion of returns $c$ that must be consumed, because it cannot be used to repay debts even if the customer wished to.

Assumption 5: $\delta(c+\theta+\gamma R+(1-\gamma) r)>1$

The project has positive net present value (NPV). Overall returns, including the part that is consumed by the customer, are bigger than the level of investment, even when the technology is generic and we discount using the customer's discount factor $\delta$.

\subsection{Bargaining}

We assume the following simple bargaining process to determine the cash flow structure between both agents: The supplier makes a "take it or leave it" offer to the customer at the beginning of every period; the customer can either accept it or switch to another supplier. Obviously, if the customer is using specific inputs and switches to another supplier, he will have to use the generic technology again.

The only subgame perfect equilibrium of this bargaining game is that the supplier will make an offer to the customer that leaves her indifferent between accepting the offer or switching to another supplier. This generates three possible different surplus distributions between the supplier and the customer, depending on whether the customer is using the startup technology, the mature technology for the first time or the mature technology after the first time.

When a customer is using the startup technology that uses generic inputs, suppliers are perfectly interchangeable. This means that the customer has in fact all the bargaining power in the relationship, since the customer can costlessly search until he finds the supplier that sells the intermediate goods at cost value.

When a customer is using the mature technology that uses specific inputs, switching to a different supplier implies that the customer would lose the advantages of the mature technology and would have to return to the startup stage again. Therefore the supplier will make a "take it or leave it" offer that extracts all the extra surplus. The customer will accept this offer as long as it is as good as the outside option of switching to another supplier. Let $p$ denote the proportion of investment that the supplier takes as surplus share, being thus $p I$ the total amount received by the supplier when the customer uses the mature technology, on top of the cost of the intermediate goods $I$.

However, there is also a special period when the customer has just been successful using the startup technology and therefore is going to use the mature technology

\footnotetext{
${ }^{12}$ However this does not necessarily mean that firms decrease size with time, since it does not preclude that $\theta+\alpha R+(1-\alpha) r-v L>1$.
} 
for the first time. At this stage, customers have a successful idea and they have to choose which supplier is going to produce the necessary specific inputs. They still face a competitive market of suppliers that know that if they are the "chosen one" they will be locked to that customer and will be able to extract some surplus from the customer in the future. Therefore when suppliers make their offer they must "bribe" the customer with a payment that corresponds to the expected discounted value of all the future payments $p I$ that will be received in further periods. We call $d$ the proportion of investment paid as "bribe" to the customers; so, in this first mature period, the customer pays $I$ in exchange for inputs, but receives $d I$ from the supplier. Note that this cash flow look precisely like a debt contract; $d I$ can be seen as a loan that suppliers make to their customers when they start using specific technology, while $p I$ are the payments of interests and repayment of capital that the customer will make in future periods. Competition between suppliers ensures that $d I$ is determined in such a way that suppliers just break even in expected terms.

\subsection{The Customer's Investment Decision}

We begin conjecturing the following equilibrium structure: the customer invests all available funds in the project, even when in the startup stage; when the liquidity shock hits in the mature stage the supplier bails out the customer by paying the cost of the shock; the customer does not keep any precautionary saving or get any insurance against the shock to force the supplier paying for it. Through sections 2.4 and 2.5 we will find the necessary conditions for this equilibrium to exist. In section 2.6 we will derive the unique equilibrium values for the cash flows $p$ and $d$, while in section 3 we will see that this insurance agreement between the supplier and the customer is the optimal one.

We can now find expressions for the value functions of suppliers and customers. By value function we mean the Bellman equation that represents the overall expected discounted value of the future returns of a firm. We express these value functions per unit of wealth of the customer firm, so to get the overall value of the customer's firm, one has to multiply the relevant value function times the current endowment of the customer. We name $S$ the per unit value function of a customer using the startup technology, $N$ the value function of a customer using the mature technology for the first time and $M$ the value function per unit of a customer using the mature technology after the first period.

For example, if $V$ denotes the overall value function of a customer in the startup stage, the relevant expression will be: $V=w S=\delta(c I+\gamma R I N+(1-\gamma) r I S)$. That is, 
the value function of the startup stage is the discounted level of consumption at the end of this period $c I$ plus the discounted value of the future value of the firm. This future value will be with probability $(1-\gamma)$ the value of a firm with initial wealth $I r$ that still uses the startup technology, and with probability $\gamma$ the value of a firm with wealth $I R$ that starts using the mature technology. These are the relevant sizes of the firm in the next period. If firms borrow up to their collateral limit, $\theta I$ has to be used to repay bank debts; also $c I$ must be consumed, so the initial wealth of the firm in the next period will be $I r$ if this period is unsuccessful and $I R$ if this period is successful. Taking common factor $I$ and given that, as we will see later on, when a firm uses generic technology $I=\frac{w}{1-\beta \theta}$, there is an expression for $S$ that does not depend on the level of wealth of the customer's firm: $S=\frac{1}{(1-\beta \theta)} \delta(c+\gamma R N+(1-\gamma) r S)$. Remember that $S$ is the value function in present value per unit of wealth of using the startup technology, $N$ the value function on the first year when supplier and customer use the mature technology, and $M$ is the value function of the mature technology thereafter. The whole set of value functions for the customer in present value (PV) per unit of wealth is:

$$
\begin{gathered}
S=\frac{1}{(1-\beta \theta)} \delta(c+\gamma R N+(1-\gamma) r S) \\
N=\frac{1}{(1-d-\beta \theta)} \delta(c+\alpha R M+(1-\alpha) r S) \\
M=\frac{1}{(1+p-\beta \theta)} \delta(c+\alpha R M+(1-\alpha) r S)
\end{gathered}
$$

The first term of each value function is the level of leverage that the firm has in every stage, or in other words, how much the customer needs to downpay per unit of investment. To understand this term we have to see what are the effective levels of investment that maximise the amount of funds committed in the project when the customer borrows as much as possible in each stage. When customers are in the startup stage they cannot commit to repay any funds on top of the collateral value of the firm $\theta I$. The discount rate of both banks and suppliers is $\beta$; to account for some competitive advantage of banks as lenders we assume that bank lending weakly dominates supplier lending, so all collateralised credit will be lent by banks. The customers will maximise the size of their firm by investing all their wealth $w$ and the funds that they can borrow from banks $\beta \theta I$. So $I=w+\beta \theta I \Rightarrow I=\frac{w}{1-\beta \theta}$. When customers are using the mature technology for the first time they receive extra funds $d I$ coming from their suppliers, so their leverage is higher than in the search case. The level of investment will then be $I=w+\beta \theta I+d I \Rightarrow I=\frac{w}{1-\beta \theta-d}$. Finally, when customers are using mature technology 
after the first time they have to share the extra surplus with their suppliers by paying them $p I$ on top of the cost of the intermediate goods $I$. The level of leverage thus goes down and $I=w+\beta \theta I-p I \Rightarrow I=\frac{w}{1-\beta \theta+p} \cdot{ }^{13}$

The second term of each value function is firstly the discounted value of this period's consumption, which is constant per unit of investment, and secondly the future value of the firm, which depends on the kind of technology that is being used. ${ }^{14}$ There is no trace in these value functions of the liquidity shock. This is because since customers are not holding any savings they will ask their supplier to pay for this liquidity shock. Section 2.5 shows that the supplier will agree to pay it.

Is investing all possible funds the optimal strategy? Given that customers have limited borrowing capacity, the positive net present value rule (NPV) becomes a necessary condition to invest. However it is not sufficient, since customers will choose the strategy with the maximum NPV and not just any strategy with positive NPV. Two potential strategies could yield a higher NPV than investing as much as possible in the search stage. One is to split the project into a series of infinitely small ones to maximise the probability of at least one success. This is precluded by the assumption that customers can only follow one project at a time. The other strategy is an intertemporal version of the previous one and would be to invest a small amount of money in the startup project and leave the rest in a bank account until a successful idea arrives. This strategy can be excluded if the instantaneous consumption associated with investing in the startup strategy is bigger than the option value of waiting for one period to see if the project is successful.

Proposition 1 There is a threshold level $\delta^{*} \in(0, \beta)$ such that for every $\delta<\delta^{*}$ it is optimal for the customer to invest all available funds in the project even in the startup stage.

\section{Proof. See Appendix 1}

Assumption 6: $\delta<\delta^{*}$

We assume that customers have a low enough $\delta$ to commit all their available funds, even in the startup stage. In equilibrium the mature technology is going to be at least as

\footnotetext{
${ }^{13}$ We can reinterpret the cash flows between the supplier and the customer in terms of prices. The customer is effectively paying a price 1 per unit of investment when using the startup technology, a price $(1-d)$ when using the mature technology for the first time and $(1+p)$ when using the mature technology from then onwards.

${ }^{14}$ The value functions are well defined. The fact that $d$ is equivalent to a discounted flow of future returns joint with Assumption 4 guarantees that $d<(1-\beta \theta)$, so infinite investment is ruled out.
} 
profitable as the startup technology (otherwise the customer would switch to the startup technology again), so this assumption also guarantees that the customer will invest all available funds when using the mature technology.

\subsection{The Supplier's Decision}

The supplier has basically three decisions to make in the model: how much surplus to extract when supplying specific goods (determination of $p$ ); how much to offer on the first period providing specific inputs (determination of $d$ ); and finally whether to bail out the customer if the liquidity shock hits and the customer has made no provisions to face it.

We use lower-case letters to indicate the equivalent value functions of the supplier, that is $s$ is the value function of a supplier that produces intermediate goods for a supplier that uses the startup technology and so on.

\subsubsection{The Bail-out Decision}

Proposition 2 Suppliers will always pay for the liquidity shock as long as customers have no funds to pay for it and the cost of searching for another customer exceeds the cost of paying for the shock.

\section{Assumption $7 L<k R \frac{\delta(\alpha-\gamma)(R-r))}{1-\beta \theta-(\beta-\delta) \alpha R-\delta(\alpha-\gamma) r+\beta v k R}$}

This is the necessary and sufficient condition that guarantees that $L<k(R m-r s)$, so suppliers would rather pay $L$ to save their customers from failure with probability $k$ than losing them and searching for new ones. ${ }^{15}$ We will see in section 3 what would happen if the condition did not hold.

Given that the customer invests all available funds and that suppliers will bail them out when necessary, the relevant value functions for the supplier are:

$$
\begin{gathered}
s=\frac{1}{(1-\beta \theta)} \beta(\gamma R n+(1-\gamma) r s) \\
n=\frac{1}{(1-d-\beta \theta)}\{-d+\beta(\alpha R m+(1-\alpha) r s-v L)\} \\
m=\frac{1}{(1+p-\beta \theta)}\{p+\beta(\alpha R m+(1-\alpha) r s-v L)\}
\end{gathered}
$$

\footnotetext{
${ }^{15}$ If suppliers did not bail out their customers, they would have to search for a new one. Later on we will see that in equilibrium $s=0$. This means that suppliers will then bail out their customers as long as $L<k R m$. In equilibrium this condition becomes $L<k R \frac{\delta(\alpha-\gamma)(R-r))}{1-\beta \theta-(\beta-\delta) \alpha R-\delta(\alpha-\gamma) r+\beta v k R}$
} 
The value functions are expressed in NPV per unit of wealth of the customer. ${ }^{16}$ The payoffs between the supplier and the customer not only affect the level of leverage of the firm, but also represent an inflow or outflow of funds into the suppliers wealth. The term $-v L$ appears in the last two equations because if the liquidity shock hits, customers will ask for these extra funds from their suppliers and they will be willing to pay. We will also see in Section 3 that using the suppliers as liquidity providers is the optimal strategy for both suppliers and customers. Using this implicit insurance provided by suppliers dominates other alternatives such as precautionary saving or other types of insurance with third parties.

\subsubsection{The Determination of the Initial Payment from Supplier to Customer}

When using specific inputs for the first time, customers have to choose which supplier will produce these specific inputs from that period onwards. Given that suppliers are relatively abundant, the fact that they can make a "take it or leave it" offer gives them no advantage since the customers will keep on searching until they find a supplier offering a deal that implies a zero NPV for the supplier. This means that suppliers will pay a quantity of money $d I$ that makes $n=0$.

Proposition 3 d gives the customer all the discounted surplus of the relationship making $n=0$.

\subsubsection{The Determination of Further Payments from Customer to Supplier}

When the customers are already using specific inputs afterwards it is costly for them to switch to another supplier because it would mean that they would have to use a generic technology again. Because of this the suppliers can use their bargaining power to extract some of the extra surplus that a specific technology produces, as compared with a generic technology.

Proposition 4 Suppliers will extract all the extra surplus from the customer when using the mature technology after the first period, making $M=S$.

Proof. See Appendix 1

\footnotetext{
${ }^{16}$ Note that customer's value functions are expressed in PVand supplier ones are in NPV this is purely for notational convenience. The expression for $s$ is written as if the same supplier would carry on with specific production in the next period. This is not necessarily true, but later on we will see that the abundance of suppliers guarantees that $n=0$ and $s=0$, so the specificaton for $s$ is quite irrelevant.
} 
Suppliers have a trade off in the determination of $p$. On the one hand, the higher $p$ the higher proportion of surplus that goes to the supplier, but on the other hand, increasing $p$ reduces the leverage and the growth rate of the customer, thus potentially reducing the future surplus for both agents. However assumption 4 guarantees that the first effect dominates and therefore extracting as much surplus as possible is optimal from the supplier's point of view.

So suppliers will extract all the extra surplus. That is $p I$ will be such that customers are indifferent between staying with their current supplier or switching to a new one. In terms of the value functions, $p$ will be such that $M=S$.

\subsection{Equilibrium}

The equilibrium values for $p$ and $d$ must satisfy the participation constraints of the agents. That is, all supplier value functions (in NPV) must be bigger or equal to 0 and all customer value functions (in PV per unit committed) must be bigger than one. There are six value functions and eight endogenous parameters. The two other conditions necessary to solve for all the endogenous parameters of the model are $n=0$ and $M=S$ that come from the only subgame perfect equilibrium in the bargaining game.

In first place the condition $n=0$ together with equation (4) implies that necessarily $s=0$. This is quite intuitive since in the startup stage the supplier just covers costs, and depending on the outcome of production it will lead to a subsequent period that can be a startup period again or a first mature period with zero NPV. Ecuations (5) and (6) with $s=0$ fully determine the relationship between $p$ and $d$. In essence $d$ must be equal to the expected future flow of $p$ in the following periods, minus the expected payments of future liquidity shocks. So we can express $d$ as a function of the future $p$ and liquidity shock.

$$
d=\beta\left(\frac{\alpha R p}{(1+p-\beta \theta)-\beta \alpha R}-\frac{(1+p-\beta \theta)}{(1+p-\beta \theta)-\beta \alpha R} v L\right)
$$

We can define $(1+g)=\frac{\alpha R}{1-\beta \theta+p}$, which is the expected rate of growth of the customer firm (and also of $p$ ) on each following period and use $\beta=\frac{1}{1+i}$ to rearrange (7) as

$$
d=\frac{(1+g) p-v L}{i-g}
$$

This is the formula of a growing perpetuity with an interest rate $i$ and growth rate $g$. So the initial payment of the supplier $d$ is equivalent to a perpetuity that pays $(1+g) p-v L$ in the first period and grows at a pace $g$. The term $(1+g)$ appears 
in the numerator because the first payment of $p$ by the customer will be made at the beginning of the next period; thus the firm has already grown for one period, while the first payment of $L$ may occur this period with probability $v$. This seems a quite intuitive result, by paying $d$ in the first period using the mature technology, suppliers qualify for a future flow of payments that start with a payment $(1+g) p$ and grow at a pace $(1+g)$ per period. In fact $(1+g)$ is not the actual growth rate of a successful customer, but the expected rate of growth which accounts for the fact that customers are successful with probability $\alpha$. The expression for $d$ also takes into account the possible payments of the liquidity shock by the supplier.

Equation (8) together with equations (1), (2) and (3) uniquely determine the values of all the endogenous variables. ${ }^{17}$ In particular, we can express $d$ as a function of exogenous variables only:

$$
d=\beta \frac{\delta(\alpha R-v L)(\alpha-\gamma)(R-r)-(1-\beta \theta+\delta \gamma R) v L}{1-\beta \theta-(\beta-\delta) \alpha R-\delta(\alpha-\gamma) r}
$$

It is useful to define $\Delta=\frac{\beta \alpha R}{1-\beta \theta-(\beta-\delta) \alpha R-\delta(\alpha-\gamma) r}$ so the expression for $d$ becomes:

$$
d=\Delta(\delta(R-r)(\alpha-\gamma)-\beta v L)-\beta v L
$$

The initial payment $d$ is a function of two terms that have a straightforward interpretation. The first term represents the payment that the supplier receives due to the fact that she can extract all the extra "relationship surplus". It is multiplied by $\Delta$ that is a scale factor. The term $[\delta(R-r)(\alpha-\gamma)-\beta v L]$ represents how much surplus the supplier will extract from the customer in future periods. The term $\delta(R-r)(\alpha-\gamma)$ is the excess productivity of the mature technology with respect to the startup technology from the customer point of view; or in other words how much more productive is the specific technology when compared to the generic one. ${ }^{18}$ This term can also be seen as a measure of the degree of specificity of the specific technology. If either $R=r$ or $\alpha=\gamma$, the advantage of the mature technology would not exist. The first term $-\beta v L$ within the brackets accounts for potential future liquidity shocks. The second term $-\beta v L$ represents the fact that the supplier expects to pay the liquidity shock on this period if it happens. It can be interpreted as an insurance premium.

\footnotetext{
${ }^{17}$ In fact there are two possible mathematical solutions for $p, d, S, N, M, s$ and $n$, but only one has economic sense. The other one, determined by $d=1-\beta \theta$, implies infinite investment and negative profits for the customer in every stage of production.

${ }^{18}$ Investing one unit in the mature stage gives an expected value of $\beta(c+\theta+\gamma R+(1-\gamma) r)$, while investing one unit in the startup stage gives $\beta(c+\theta+\alpha R+(1-\alpha) r-v L)$. The difference between these two terms is in fact $\beta[(R-r)(\alpha-\gamma)-v L]$.
} 
The equivalent expression for $p$ is:

$$
p=\Delta \frac{(i-g)}{(1+g)}(\delta(R-r)(\alpha-\gamma)-\beta v L)+\beta v L
$$

This has exactly the same interpretation, although the scale factor is now $\Delta \frac{(i-g)}{(1+g)}$. Again there is a first term that is positively related to the extra levels of productivity when the technology is specific, plus a term that corresponds to the payment of an insurance premium in the current period. ${ }^{19}$

Investment depends on the level of wealth of the firm and the attainable level of leverage. While wealth is backward looking and consists of the accumulation of past profits, leverage is forward looking, so $d$ depends on the future profits that the supplier can extract. This situation generates an amplification mechanism. An increase of productivity of the specific technology will increase the surplus extracted by the supplier and therefore the level of leverage of the customer. This will increase the profits of the customer, thus increasing the surplus extracted by the supplier again, and so on. The scale factors $\Delta$ and $\Delta \frac{(i-g)}{(1+g)}$ summarise this amplification effect in the following way. If the mature technology became more productive by one unit (or the startup technology became less productive by one unit), $d$ would grow by a factor of $\Delta$ and $p$ would grow by a factor of $\Delta \frac{(i-g)}{(1+g)}$.

The whole picture of the equilibrium arrangement between the supplier and the customer is as follows: the existence of a technological link between them makes the supplier get some (in this case all) of the extra surplus of the mature technology every period. This guarantees the supplier a growing flow of income, which will only stop if the link is lost. As the customer can choose which supplier is going to get this flow of funds, the chosen supplier gives the customer in advance the expected future value of this surplus share, thus making the implicit agreement look like a debt contract. This is an equilibrium result and no actual contract needs to be written to enforce the agreement. So the fact that returns may not be verifiable does not preclude the supplier lending to the customer. The levels of debt depend positively on how important the link is between the supplier and the customer. In the extreme case when suppliers can be perfectly substituted, trade credit does not exist.

From an efficiency point of view this equilibrium is also the optimal arrangement for the customer. Given that the customer has a technology with positive NPV, it is optimal

\footnotetext{
${ }^{19}$ Note that this expression for $p$ is not fully exogenous, as $g$ contains $p$ in its denominator, the full exogenous expression for $p$ is $p=\frac{(1-\beta \theta-\beta R \alpha)\left[(R-r)(\alpha-\gamma)-\frac{\beta}{\delta} v L\right]+\frac{1}{\Delta} R \alpha \beta v L}{\frac{1}{\Delta} R \alpha-(R-r)(\alpha-\gamma)+\frac{\beta}{\delta} v L}$
} 
to bring to the present as many funds as possible and invest them all. In equilibrium, collateralisable returns are fully brought to the present through bank credit, and also some of the non-contractible returns are brought to the present via trade credit. On top of the debt-like agreement, suppliers also provide insurance against possible liquidity shocks. In Section 3 we also show that the insurance arrangement is also optimal.

\section{Supplier Insurance Versus Other Forms of Insur- ance}

So far, we have conjectured that the customer does not take any precautions against a possible liquidity shock, in order to force the supplier to pay for it. We have seen that the supplier will agree to pay it as long as the cost of the shock is sufficiently small when compared with the rents being extracted from the customer. Customers have other potential strategies to deal with the payment of the liquidity shock. In particular, they could have some precautionary saving or else they could sign an insurance contract with a third party such as a bank. In this section we show that the optimal strategy for customers is to use their suppliers as insurance providers.

The first strategy that customers could use to face the liquidation shock is to have some precautionary saving. That is, they could save in a bank account the discounted full size of the shock $\beta L I$ and use it if the shock hits. If the shock does not happen these funds are added to the initial wealth of the firm at the beginning of the next period. The other possible strategy is contracting insurance with a third party deep pocket. We call this type of insurance bank insurance and it consists of paying a fair insurance premium $\beta v L I$ per period, to a bank who will pay the liquidity shock whenever it happens.

In pure cost terms, bank insurance and supplier insurance are equivalent. However, as we will see, supplier insurance will strictly dominate bank insurance in the presence of any contracting friction, verifiability problems or renegotiation. On the other hand, precautionary saving is more costly than the other two strategies. Comparing the precautionary saving strategy with the bank insurance, precautionary saving is equivalent in expected returns to paying an insurance premium $\beta v L I$ and saving an amount $\beta(1-v) L I$ for next period. But we know by proposition 1 and Assumption 6 that saving is suboptimal with respect to investing, so precautionary saving is therefore dominated by writing an insurance contract with a third party, that only involves paying 
the premium $\beta v L I$. So supplier insurance and bank insurance dominate precautionary saving. ${ }^{20}$

The main advantage of supplier insurance with respect to bank insurance is that it is an equilibrium result of the interaction between both commercial partners. It is renegotiation proof, there is no need for a written contract and the supplier will always bail out the customer, as long as the customer has not got any other way to face the shock, and the continuation value for the supplier exceeds the cost of bailing out the customer. Even if the shock is sometimes non verifiable and a written insurance contract is not always enforceable the customer can still use the supplier as lender of last resort.

Also, to some extent, supplier insurance is unavoidable. Suppliers cannot credibly commit not to bail out their customers if they experience a liquidity shock and they do not have any funds or alternative insurance to cover it. So there will always be an insurance premium included in the cost of trade credit. The only way to avoid paying this premium is if the customer takes alternative precautions and can prove to the supplier that no bail out will be needed. Therefore the implicit insurance contract that the supplier offers will necessarily be the dominant strategy whenever the liquidity shock is not verifiable. It will also be the dominant strategy when the shock is verifiable and an insurance contract can be written with a third party, but the customer cannot "convince" the supplier that this insurance exists. This may prove a difficult task as the customer can secretly cancel the contract with the third party. If the supplier believed that she would still have to pay for the shock anyway she will still charge the insurance premium, thus the customer would be paying twice for the same cover. Any kind of contracting costs would also give the advantage to supplier insurance.

Proposition 5 If customers can credibly commit to get bank insurance then bank insurance is equivalent to supplier insurance in cost terms.

\section{Proof. See Appendix 1}

Both banks and suppliers are deep pockets with the same discount rate. Both expect to make zero profits on average in their interaction with the customers. So it is an intuitive result that the cost of getting insurance from either of the agents is the same.

One assumption that would give suppliers a cost advantage over third party insurers would be if suppliers and customers were both cash constrained and had a lower discount factor than banks. ${ }^{21}$ In this case suppliers would be cheaper insurers than banks because

\footnotetext{
${ }^{20}$ See Appendix 1 for details.

${ }^{21}$ For example if suppliers were also cash constrained and had access to a liquid and reversible produc-
} 
they would discount the insurance premium at more favourable terms. This effect would also be amplified by the multiplicator $\Delta$ (see Section 2.6).$^{22}$ Supplier's impatience would also make bank collateralised loans strictly preferred to supplier ones. The disadvantage of this alternative model is that the cash holdings of the supplier have to be explicitly modelled. ${ }^{23}$ We opted for this version with equal discount rates to keep the exposition simple.

So far we have followed the interpretation of $L I$ as a monetary payment. However we could also see it as the cost of a delay in production. This interpretation may be closer to the phenomenon of late payment. If a customer production is delayed, suppliers receive the next payment of $p$ later on. The cost of this delay can be summarised by $L I$. If we stick to this interpretation, supplier insurance would be completely unavoidable. Suppliers would face the cost of this delay and they could cover themselves with a third party if they wish to, but no insurance scheme on the customer's side would be feasible.

Within the monetary interpretation of $L I$ the only situation in which supplier insurance would not be available would be if Assumption 7 did not hold. In this case, the link between the supplier and the customer is too weak. The supplier would rather lose the customer than pay $L I$. If this was the case, bank insurance would be the optimal strategy for the customer.

\section{Implicit Interest Rates}

Now we have a justification for the high interest rates paid by customers for their trade credit. The interest rate paid includes two premia that are not included in a bank credit.

The first premium is a default premium and it is related to the ability of suppliers to claim back debts, and also related to the extra risk that suppliers face. In the model, bankers are lending with a collateral claim and their loans are virtually risk free. However, suppliers are lending on the basis of their extra ability to get paid later on, thanks to the technological specificity that links them with their customers. If this specificity is lost in a bad production period, suppliers will not be able to extract any

tion technology that yielded more than $\frac{1}{\beta}$ units of non verifiable returns per period, per unit invested, where they could invest their "spare" funds.

${ }^{22}$ Without going into the details of this alternative model; we can infer from the final expressions for $p$ and $d$ that if, for example, suppliers had also discount rate $\delta$, the cost advantage of supplier insurance would be $(\beta-\delta)(1+\Delta) v L$ in the case of $d$ and $(\beta-\delta)\left(1+\Delta \frac{(i-g)}{(1+g)}\right) v L$ in the case of $p$.

${ }^{23}$ For example, the structure of the model has to preclude that the supplier could strategically consume all her funds to commit credibly not to bail out the customer. 
surplus from the relationship again. So from the point of view of suppliers, trade credit looks like debt with default risk, and thus they have to charge a higher interest rate to compensate for this extra risk. In reality, even though banks lend not only on collateral, it seems reasonable to think that bank credit is in general safer than most trade credit.

The second -and perhaps the most interesting- reason why trade credit should be more expensive than bank credit is that an insurance premium is charged by suppliers to compensate for the cost of providing extra liquidity to their customers in case that they have temporary liquidity needs. The fact that suppliers may be asked to provide extra funds, or to extend the maturity of existing debts without charging an extra penalty is foreseen in advance by them and they ask for a compensation in advance to cover the expected costs of these future bail-outs.

How can we calculate an explicit expression for the interest rates charged on trade credit in the model? One way is to consider the financial relationship that links the supplier and the customer as a perpetuity with a risk of default. We can find the interest rate $\rho$ that makes $d$ the fair price of a perpetuity that pays $p$ times $\frac{R}{1-\beta \theta+p}$ on the first period and then has a growth rate of $\left(1+g_{1}\right)=\frac{R}{1-\beta \theta+p} \cdot{ }^{24}$

So $d$ can then be expressed as:

$$
d=\frac{p\left(1+g_{1}\right)}{(1+\rho)}+\frac{p\left(1+g_{1}\right)^{2}}{(1+\rho)^{2}}+\frac{p\left(1+g_{1}\right)^{3}}{(1+\rho)^{3}}++\frac{p\left(1+g_{1}\right)^{4}}{(1+\rho)^{4}} \ldots
$$

Our interest is to calculate the rate $\rho$ that makes this equation hold. We already know that $d$ is such that suppliers break even when discounting at a rate $i$, so the difference between $\rho$ and $i$ will be the default premium and the insurance premium paid by customers. We can re-express $d=\frac{\left(1+g_{1}\right) p}{\rho-g_{1}}$ in a similar fashion to equation (8).

The expression for $\rho$ is then:

$$
\rho=\frac{\left(1+g_{1}\right) p}{d}+g_{1}
$$

And the difference between the market interest rate $i$ and $\rho$ is:

$$
\rho-i=\frac{\left(1+g_{1}\right) p}{d}+g_{1}-\frac{(1+g) p-\nu L}{d}-g
$$

We can now see the premium of the implicit interest rate $\rho$ over the bank lending rate that we have normalized to zero:

\footnotetext{
${ }^{24}$ Note that $\left(1+g_{1}\right)$ is the actual growth rate of the firm if successful and should not be confused with $(1+g)=\frac{R \alpha}{1-\theta+p}$ which is the expected rate of growth before knowing if the firm is going to be successful or not.
} 


$$
\text { Premium }=\rho-i=(1-\alpha) g\left(1+\frac{p}{d}\right)+\frac{\nu L}{d}
$$

The premium is composed of two terms. The first element of the premium is a default premium. Suppliers know that if the customer firm is unsuccessful they will not be able to receive any more payments from the customer. Default occurs with a probability $(1-\alpha)$ and $g\left(1+\frac{p}{d}\right)$ accounts for the actual loss of future income after default. Secondly, $\frac{\nu L}{d}$ is an insurance premium that measures the foreseen payments that the supplier may have to make to bail out customers with liquidity problems. The term is just the expected cost of the liquidity shock over the amount lent. These two premia explain the high cost of borrowing from suppliers. The high implicit interest rates of trade credit with respect to bank credit account for a higher risk of default of trade credit and the possibility that customers need to be bailed out or incur late payments.

\section{Empirical Analysis}

The model of Sections 2 and 3 explains some of the stylized facts regarding trade credit such as the apparently high interest rates implicit in the discount for early payment and the existence of trade credit. Moreover, the model also has a series of testable implications that can be used to assess its relevance and compare it with other competing theories regarding trade credit. Three main empirical implications of the model are tested in this section.

Firstly trade credit should grow as the link between a customer and a supplier becomes tighter: higher levels of trade credit are expected when intermediate goods are very specific, when suppliers have private information about their customers or in general when suppliers are costly to substitute. ${ }^{25}$ In the model, this is a direct consequence of Expression ??. Ideally one would like to have an unambiguous measure of this link, but given the diverse nature of the relationship between suppliers and customers, it is difficult to find a single measure that summarizes it. I overcome this problem by using

\footnotetext{
${ }^{25}$ The model does not address the idea of suppliers having superior information about their customers directly. However any kind of informational advantage that would make customers more productive with their long-term supplier than with an alternative one would fit in the model. This is not to be confused with informational asymmetries in the spirit of standard relationship lending models like in Biais and Gollier (1997) where suppliers have an advantage in determining the creditworthiness of their customers.
} 
a non parametric analysis that uses as a proxy for the degree of relationship between suppliers and customers the age of recently created firms.

Secondly, as seen in Proposition ??, firms experiencing liquidity problems should use their suppliers as lenders of last resort. I explore this relationship through two main specifications. A non parametric analysis that links measures of trade credit and firm performance and a regression analysis that relates trade credit to liquidity measures.

Finally, the proportion of trade credit used with respect to other forms of finance should depend on the level of collateral that firms have. The higher the level of collateralizable assets, the lower the expected proportion of trade credit. This result is almost imposed in the assumptions of the model. However it is relevant to test this assumption, especially given that alternative theoretical models have given little or no attention at all to the determination of the "mix" between trade credit and other forms of credit. ${ }^{26}$

To test the implications of the model I use a sub-sample of the FAME-Bureau Van Dijk database. This database is collected by Jordans and Bureau Van Dijk for commercial use and it includes balance sheet data, profit and loss statements and some complementary information on 210,000 firms from 1993 until 1999 including many small and new-born firms. I restrict the analysis to manufacturing firms, retailers and wholesalers reducing the sample to an unbalanced panel of approximately 55,000 firms with an average of 4.5 observations per firm. ${ }^{27}$

This database presents two particular characteristics that make it specially appealing for this problem. In the first place, the dataset contains both quoted and not quoted firms as well as many small firms. Secondly, the high number of observations is ideal to perform non-parametric estimations that are particularly important when some of the implications tested are highly non linear. Using a panel also allows for controlling for the presence of individual heterogeneity and for the possible endogeneity of trade credit decisions. We use individual fixed effects and a GMM instrumental variables approach in all the panel regressions to address these issues.

The remaining parts of this Section are as follows. In Section 5.1 I relate the levels of trade credit taken to the age of new born firms; Section 5.2 explores the relationship between firm performance and trade credit taken; finally Section 5.3 investigates how

\footnotetext{
${ }^{26}$ The change in trade credit over assets as a function of collateral can be seen in the model by taking the derivative of Expresion ?? with respect to $\theta$. The derivative is positive and grows with the degree of the link.

${ }^{27}$ I drop firms in sectors such as agriculture, fishing, mining, financial intermediation, other services, real estate, public administration etc, because these are sectors in which buying intermediate goods from a supplier represents a small part of the firm inputs and therefore trade credit is of little relevance.
} 
trade credit relates to the levels of collateral and liquid assets available to customers.

\subsection{Trade Credit and Age of the Firm}

The model predicts that trade credit should grow as the links between the supplier and the customer grow. Ideally one would like to have a measure of the length of a supplier-customer relationship regardless of the age of the customer firm, unfortunately this information is not available in this dataset so newborn firms are used to extract this information. In the model the build up of the relationship takes the form of a discrete jump that follows a stochastic process: the level of trade credit of a new born firm is zero up to a certain point in time, when the level of credit suddenly rises up to a level $d_{m} I$. In practice this process may be gradual as the links between a supplier and a customer build up during long periods. To approximate this gradual process I use the model in Section 2 to simulate the levels of trade credit of a "representative" firm instead of using a single firm. Figure 1 shows the average level of trade credit over assets of a population of firms that are all "born" at the same time. ${ }^{28}$ This would correspond in practice to a link that takes time to build and grows gradually. For example if the supplier and the customer get to know each other and there is a process of learning by doing or if the customer's product gradually changed towards a final and most productive specification that needs intermediate goods which are increasingly specific.

To test empirically whether this hump shape is actually present in the dataset I run a non-parametric regression which shows the non linear relationship between the level of trade credit over assets and the age of the firm. In particular I run a local linear regression since it is the non-parametric regression that has the best asymptotic properties for the studied problem. In essence the local linear smoother is a way to summarize a scatterplot graph into a non-parametric function. ${ }^{29}$

Figure 2 shows a local linear regression for the whole sample, with a window of 5000 firms and equal weights for each observation. ${ }^{30}$ I compute the standard deviation of

\footnotetext{
${ }^{28}$ The simulation is done for 5000 firms and 20 years, the parameters are $\gamma=0.1, \alpha=0.9, \theta=0.7$, $r=0.15, R=0.35, \beta=0.85, v=0.2 ; L=0.05$.

${ }^{29}$ See Fan (1992) for a thorough explanation of the local linear estimation. This type of non-parametric estimation has the advantage with respect to other techniques (such as a Nadaraya-Watson estimator Nadaraya, 1964 and Watson, 1964) of being a consistent estimator even in the tails of the estimation and in the presence of frequency clustering among the data. This is particularly useful here, where the results for the firms in the left tail of the estimation are the most important and considering that the density of firms in different age intervals of the sample is not constant.

${ }^{30}$ The results of the estimation are robust to different choces of bandwith. $n=5000$ has a good balance between the flexibility of the estimator and its precision.
} 
the estimator and show a $95 \%$ confidence interval. As shown, the level of trade credit grows until the third year of the age of the firm, it stays at this maximum level until the fifth year, and then gradually goes down during the next periods. This is consistent with the prediction of the model. Customers do not receive much credit from their suppliers straight away but it takes time to build up the link with their suppliers that is necessary for borrowing. So far, other empirical studies based on linear regressions found a negative relationship between trade credit and age. This corresponds in Figure 2 to the negative slope from the fifth year onwards. The non-linear approach, also allows us to identify the initial increase of trade credit in the early years of a supplier-customer relationship. The $95 \%$ confidence interval reflects the lower density of firms in the left tail but it is sufficiently narrow to accept a hump shaped pattern.

Two features seem to make the results of Figure 2 slightly different to the one predicted by the simulation. The first difference is that the levels of trade credit of new-born firms are not zero. In the model, trade credit of a new-born firm is zero because trade credit is assumed to be completely unenforceable and there are no links between suppliers and customers. In reality trade credit is not completely unenforceable by law, so even if the levels of specificity of suppliers for new firms are low there is still scope for credit. In addition, significant links between suppliers and customers may already be in place at the very beginning of their interaction; for example, if there are sunk costs or search costs associated with finding a supplier or if the customer already has a very detailed blueprint of the necessary intermediate goods, even at very early stages of the firm life. Another reason why there is scope for positive levels of trade credit use for new-born firms is that it can be used as a transaction device. ${ }^{31}$ The second main difference between the simulation and the results of the non-parametric regression is that the level of trade credit also seems to go down as the firms grow older after the fifth year. This means that trade credit is shrinking, or at least that it is not growing at the same pace as the assets of the firm. By checking the evolution of other parts of the balance sheet with age, I found that this decrease is mainly due to the growth in retained earnings that allows firms to substitute trade credit with cheaper sources of finance. It is also due to the fact that as firms get older their expected rate of investment goes down, so they no longer exhaust their borrowing capacity and they start reducing their most expensive loans (i.e. trade credit).

\footnotetext{
${ }^{31}$ Ferris (1981) sees trade credit as a means of payment to reduce transaction costs when the timing of the arrival of new supplies is uncertain. This is consistent with the existence of a free delayed payment period like the first ten days in the "2-10 net 30" deal. However, the model remains silent about why trade credit is so expensive and why firms are willing to pay such costs.
} 
The use of a local linear regression has the advantage of a very flexible estimation of the non-linear structure of this problem. However, it has the major drawback of being a bivariate analysis that does not correct for the possible influence of other variables. The results may be due not only to the build up of a link between suppliers and customers, but may be driven by the existence of other variables such as size or the level of activity of the firm that are correlated with both age and trade credit. To make sure that this is not the case, I also show the results of spline regressions that are not as flexible as the local linear smoother, but allow to control for other relevant variables. Spline regressions are just linear regressions in which a "spline" variable is constructed to estimate a non linear relationship as piecewise linear. The results of this regression are shown in Figure 3. To generate it I use one spline for each year of age between zero and 20, and linear controls for size, inventories, collateral levels, deposits and year dummies measured as in Section 5.3 are introduced.

The results are not qualitatively different to the ones shown in Figure 2. Again there is a rise of trade credit in the early years of life of a firm, that is now sharper in the second year than in the first one, and stabilizes around the third to fifth year of age of the firm, leading to a substitution in the next years of trade credit by other sources of finance. The rise of trade credit is still significant in the spline regression after controlling for the levels of activity of the firm and its size.

Even though the time series interaction between trade credit and bank credit is not studied explicitly, the results of the previous regressions, and the implications of the basic model shed some light on the issue of whether trade credit and bank credit should be considered as substitutes or complementary to each other. While firms are financially constrained extra levels of trade credit may allow firms to increase their available bank credit through higher collateral value. Similarly, higher levels of bank credit may increase the purchases made to suppliers, increasing the size of the purchases made to customers and therefore the amount of available trade credit. So for constrained firms, trade credit and bank credit will behave as complementaries. This would correspond with the upward sloping part of the graph. However, if firms are not cash constrained typically bank and trade credit will behave as substitutes. Whenever a firm that uses both bank and trade credit has extra borrowing capacity with banks it will substitute some costly trade credit with cheaper bank credit. This would correspond with the downward sloping part of the graph. 


\subsection{Trade Credit and Firm Performance}

The model predicts that when the links between suppliers and customers are strong, suppliers will have an incentive to give financial help to their customers who experience temporary liquidity shocks. This again predicts higher levels of trade credit when the relationship surplus between the buyer and the seller is big, so it is consistent with the previous results, but there are more detailed ways to test if this financial support is present in reality.

The high cost of trade credit induces customers to use it as a financial instrument only when other forms of finance are scarce. When firms are growing fast and undertaking new investments, trade credit should grow; just because other forms of finance may not be available. Also when customers experience problems they may need to finance a higher proportion of their purchase on trade credit and use late payment as a way to increase the amount of finance that they receive from their suppliers. Suppliers will be willing to finance their customers in trouble as long as the value of their relationship with them is higher than the cost of helping them. These two effects imply an expected "U" shaped distribution of the relative levels of trade credit with respect to a "performance measure". The firms that are doing best and the ones suffering slight problems should be the ones that borrow more from their suppliers. To check if this relationship holds in reality, I run a local linear regression relating the level of trade credit over assets to the growth rate of the assets of the firms in the sample. ${ }^{32}$ The reason why I use asset growth rates as a "performance measure" is that it is the best variable that one can obtain from balance sheet data. The profit and loss statements are only available for a small subsample of firms. It is also the variable that is closest in interpretation to the growth rates of the model. This estimation is shown in Figure 4. The predicted U-shaped relationship is confirmed by the data.

Trade credit is highest for the firms that grow at a higher pace. This is consistent with the fact that trade credit is relatively expensive and firms use it only when they need to use all their borrowing capacity and have exhausted other available sources of finance (i.e. when they experience high growth rates). Also, new-born firms are the ones with higher levels of growth and higher levels of trade credit, as seen in Section

\footnotetext{
${ }^{32}$ Firms that have no activity, have little or no trade credit (as they do not purchase anything). They also have growth rates that are close to zero. For this reason I have not included in the estimation firms that declare to be dormant, firms that are pure asset holders, declare zero sales or post exactly the same balance sheet for two consecutive years to avoid the chance that they could artificially drive the results. Including these firms would induce us to estimate an unrealistic low level of trade credit for low growth firms.
} 
5.1. The average borrowing capacity limit seems to be around $22 \%$, while the minimum average borrowing level is around $14 \%$. Note that these levels seem to coincide with the ones of Figure 2. This does not mean that these are the minimum and maximum levels for any individual firm but only shows what is the typical range of trade credit use as a proportion over total assets.

The most interesting feature of the results in Figure 4 is on the left-hand side, where firms that experience slight problems (small-medium negative growth rates up to -30\%) seem to have relatively high levels of trade credit when compared with firms that have low growth rates. This means that suppliers still lend to these firms that are suffering problems, so trade credit grows or at least does not shrink at the same rate as assets do. This is evidence in favour of suppliers seen as lenders of last resort. The help that suppliers provide to their customers is probably not given by a monetary transfer, but most likely by accepting late payment of already extended debts and supplying more intermediate goods on credit. However, suppliers do not seem to give extra finance to firms that experience serious problems (i.e. firms that halve their assets or worse) in the far left-hand side of the figure. For these firms, trade credit decreases even more than assets, so there is a reduction of trade credit over assets for firms experiencing strong problems that comes from the supply side of it. This can be explained within the model by a liquidity shock that is too big to be paid by suppliers, or in other words a shock that violates Assumption 7. Finally, firms in the middle range (zero growth and small positive growth rates) have relatively low levels of trade credit. In the model this is justified because these are unsuccessful firms with low links with their suppliers. In practice, other complementary reasons may also be causing this slump. First, low growth firms may have lower finance needs, so they use cheaper ways of finance than trade credit. Second, firms that are not growing much may be buying relatively low levels of intermediate goods, thus making it more difficult for them to have high levels of trade credit.

Again, one could be worried about the bivariate nature of the previous estimation. To see if the results are biased because I do not control for other variables, I also show the results of a spline regression that has other linear regressors. For Figure 5 I use a spline regression on asset growth rate where each spline spans over $5 \%$ of the total sample, controlling for size, inventories, collateral levels, deposits and firm dummies. ${ }^{33}$

The results of Figure 5 do not differ from the ones obtained in Figure 4. The firms

\footnotetext{
${ }^{33}$ To allow for extra flexibility of the estimation we have split the first left hand side spline in two, so each one represents $2.5 \%$ of the sample.
} 
that use trade credit more extensively seem to be the ones that are growing at a very fast pace, but also the ones that are experiencing temporary problems. This result again points in the direction of suppliers helping their customers in need of extra finance, especially in periods of financial distress. Note that the levels of trade credit over assets also go down in this regression for the worst firms of the sample, (i.e. the ones with negative growth rates of $-30 \%$ or worse), so suppliers are able to recover their debts even faster than the rate at which assets are shrinking. As a whole the results of this regression confirm those in Figure 4.

\subsection{Collateral and Liquid Assets}

This section analyzes the effects of collateral and liquid assets on trade credit, while controlling for other relevant variables. In the model all bank credit is fully collateralized while trade credit corresponds to risky and completely unsecured debts. In practice, this absolute dichotomy need not be true; part of bank lending is not secured by collateral and trade creditors can sometimes claim the goods supplied by them in case of default. This section explores how the proportion between trade credit and other forms of debt evolves as firms have more or less collateral, to assess whether the modelling assumption is reasonable. It also checks if the levels of trade credit rise when firms experience liquidity shocks. The level of cash and deposits that the firm has is used as a way of measuring the liquidity needs of the firm. A priori one would expect that a firm will use less trade credit the higher the level of cash and deposits.

I report regressions that use two alternative dependent variables: the ratio of trade credit over total debt (including trade credit) and the proportion of trade credit over assets. This second dependent variable is introduced to avoid a possible conmovement of short-term trade credit and other debt instruments when firms experience liquidity shocks. ${ }^{34}$

Trade credit terms are very stable along time within an industry and also at a firm level, generating a lot of inertia in trade credit use. To capture this inertia I use fixed effect regressions that control for any permanent unobserved heterogeneity at a firm level that shifts in an additive way the use of trade credit. Even though all regressions include time dummies, there could be different trends at a sector level that

\footnotetext{
${ }^{34}$ In the current parametrization of our model firms do not hold any precautionary saving. However this may happen in equilibrium or if there is a small probability that a liquidity shock may exceed the value of the relationship for the supplier (i.e. $L>m$ ). Firms may also hold some liquid assets for transaction purposes (Ferris 1981).
} 
could artificially drive the results. That is why sector time trends are also included at a 3 digit SIC level. Furthermore, given that the estimates could be subject to endogeneity problems I also report the Arellano-Bond (GMM) estimator that allows the estimation of a fixed effect regression that also includes a lagged dependent variable. The ArellanoBond estimator uses an instrumental variable GMM procedure to avoid the problems of endogeneity associated with using a fixed effects estimator when there is potential autocorrelation of the dependent variable. ${ }^{35}$ The Arellano-Bond estimator also corrects for any contemporaneous endogeneity problems and not just for the ones associated with the inclusion of a lagged dependent variable. Random effects (GLS) estimations were also run. Given that the Haussman test rejected the hypothesis of equality of coefficients in both regressions, these GLS estimators are not reported.

The independent variables are four control variables and two variables of interest. The variables of interest are the amount of tangible assets (land, buildings, machinery, vehicles, etc.) over total assets as a measure of the level of collateral, also the proportion of cash and deposits over total assets that the firm has as a measure of the liquid assets of the firm, to account for the liquidity needs of the firm. The control variables are the log of the assets of the firm (in thousand pounds); used as a control variable to correct for the size of the firm. The proportion of inventories that the firm holds over assets reflects the level of activity of the firm. ${ }^{36}$ The level of inventories over assets allows to control for the level of activity of both big and small firms. I also include as control variables year dummies, the age of the firms in years and their asset growth rate to have a measure of firm performance. ${ }^{37}$ The results of these last two variables are not reported as the last two sections already provide a more detailed analysis of them. The results of these regressions can be seen in Table 3 .

The results in Table 3 show that the prediction of the model with respect to the effect of the level of collateral is confirmed by the data. Columns 1 to 3 show the results of regresions that use as dependent variable the ratio of trade credit to total debt. The result regarding collateral is that firms have a higher level of collateral use a lower proportion of trade credit and higher proportions of bank credit and other forms

\footnotetext{
${ }^{35}$ The Arellano-Bond estimator allows for the unbiased and consistent estimation of the coefficients of a model of the type $y_{i t}=\delta y_{i t-1}+\beta x_{i t}+\varepsilon_{i t}+\delta_{i}$ where $\varepsilon_{i t}$ is a standard error term and $\delta_{i}$ is an individual error term, by taking first differences and using several lagged dependent variables (in first diffferences also) as instruments. See Arellano and Bond (1991).

${ }^{36}$ Another possibility could be to use the level of sales, unfortunately many firms in the sample do not report their level of sales, and this is particularly true for the smaller firms of the sample.

${ }^{37} \mathrm{I}$ dropped observations with asset growth rates higher than $100 \%$.
} 
of finance. The coefficients associated with collateral are important also in quantitative terms; moving from the 10th percentile to the 90th percentile of the collateral over assets variable would mean a decrease of the level of trade credit over total debt between $4.9 \%$ and $6.5 \%$. This supports the assumption of bank credit being highly related to collateral while trade credit corresponds to unsecured debts. In the UK the effective level of collateral attached to trade credit is very low, suppliers are very rarely able to reclaim the goods delivered in case of default and the recovery rates in case of liquidation are also very low. ${ }^{38}$ The coefficient of lagged trade credit over total debt on the current ratio of trade credit over total debt in the GMM regression is 0.51, showing that there is a strong autocorrelation of trade credit across periods.

The level of trade credit over total debt decreases when firms reduce their level of cash and liquid assets; this seems contradictory with the idea that trade credit can be a tool that firms use to overcome liquidity restrictions, however the result could be due to the fact that other sources of finance also increase when the firm experiences temporary liquidity shocks. To clarify this point, columns 4 to 6 show the results when we use as dependent variable the level of trade credit over total assets. This variable should not be influenced by this conmovement

The result with respect to liquid assets is positive and statistically significant for the regression of trade credit over total assets. Buyers use more trade credit when they are more liquidity constrained. This seems an obvious strategy given the high cost associated with getting credit from your suppliers. The traditional wisdom of "pay late, get paid early" does not seem to be optimal when one takes into account that the early payment discounts are commonly very generous.

Again higher levels of collateral are associated with a lower proportion of trade credit and higher proportions of bank credit and other forms of finance, although the coefficient is not significant in the first two regressions. Note that while the model predicts that the proportion of trade credit over total debt should decrease with the proportion of collateral, the predictions of the model regarding the levels of trade credit over assets are ambiguous, since the composition effect of a lower proportion of trade credit/debt could be compensated by a higher level of leverage. However, the two regressions seem point in the same direction. Again the GMM estimation shows a strong autocorrelation of trade credit through different periods.

\footnotetext{
${ }^{38}$ Franks and Sussman (1999)
} 


\section{Conclusions}

We have shown that the existence of trade credit may be justified as a result of the interaction between a supplier and a customer that engage in specific production processes in a context of limited enforceability of debts.

A certain technological specificity gives suppliers an advantage in enforcing noncollateralised debts. This advantage allows them to lend beyond the maximum amount that banks are willing to lend. As a result, trade credit can exist even in the presence of a competitive banking sector. Customers are rationed in the bank credit market, so trade credit allows them to increase their leverage. The extra enforceability power of suppliers comes from the fact that they can threaten to stop supplying intermediate goods to their customers. In the presence of some kind of product specificity or a certain link between the supplier and the customer, finding a new supplier is costly, so customers will pay back their debts before switching to another supplier.

However, this link works both ways. Not only are customers more willing to repay their suppliers, but suppliers will forgive debts and extend the maturity period of their credit when customers experience temporary liquidity shocks that may threaten their survival. In practice; firms in financial distress generally delay the payment of their due trade credit. This late payment rarely carries a monetary penalty, nor a cut in the flow of intermediate goods to the debtor. Their suppliers are effectively providing liquidity (as a continuous flow of intermediate goods sold on credit) as a means of increasing the survival chances of their customer. The model predicts that this type of insurance is more likely when the links between buyers and sellers are stronger, or in other words suppliers are more likely to help their customers if it is very costly for them to find a new customer.

Even though we speak about technological specificity, the ties between the supplier and the customer are not explicitly modelled. However, we can think of broader industrial links that are not strictly technological that would still sustain the results of this analysis. Any kind of sunk cost (legal procedures, bargaining costs, search costs, etc.) attached with starting a new commercial relationship, or production processes that benefit from learning by doing, or the build-up of reputation and trust between commercial partners would have similar effects.

Some of the implications of the model are supported by the empirical evidence. The evolution of trade credit levels with the age of the firm shows that suppliers do not lend much to their customers at the beginning of their commercial relationship, but the levels 
of credit build up as the relationship evolves. The building up of trade credit in the early years of a firm reinforces the interpretation of trade credit as a result of the existence of some degree of specificity between a supplier and her customers.

The empirical results also show that trade credit is used in the margin, when other forms of credit have already been exhausted. High growth firms, that need as much finance as possible, together with firms experiencing liquidity problems are the ones that get a higher proportion of credit from their suppliers. This seems a reasonable strategy given that trade credit is a relatively expensive form of finance. Finally, the proportion of trade credit with respect to other forms of finance seems to be highly dependent on the levels of collateral. Higher levels of collateral mean a lower proportion of trade credit. This is consistent with the hypothesis of firms exhausting other available forms of credit before using trade credit as a source of finance. Theseesults are consistent with the theoretical model developed in the first part of the paper and challenge some of the results of other theoretical models. 


\section{References}

[1] Berger, Allen N.; Udell Gregory F. (1998) The economics of small business finace: The roles of private equity and debt markets in the financial growth cycle Journal of Banking and Finance 22, 1998 pages 613-673

[2] Biais, Bruno; Gollier, Christian (1997) Trade Credit and Credit Rationing Review of Financial Studies; 10(4), Winter, pages 903-37.

[3] Bolton, Patrick; Scharfstein, David S. (1990) A Theory of Predation Based on Agency Problems in Financial Contracting American Economic Review; 80(1), March, pages 93-106.

[4] Brennan, Michael J.; Maksimovic, Vojislav; Zechner, Josef (1988) Vendor Financing Journal of Finance; 43(5), December, pages 1127-41.

[5] Brick, Ivan E.; Fung, William K. H. (1984) Taxes and the Theory of Trade Debt Journal of Finance; 39(4), September, pages 1169-1176.

[6] Elliehausen, Gregory E.; Wolken John D. (1993) The Demand for Trade Credit: An Investigation of Motives of Trade Credit Use by Small Businesses Board of Governors of the Federal Reserve System. September

[7] Emery, Gary W. (1984) A Pure Financial Explanation for Trade Credit Journal of Financial and Quantitative Analysis Vol 19 (3) September Pages 271-285.

[8] Fan Jianquing (1992) Design-adaptive non-parametric Regression Journal of the American Statistical Association Vol 87 No 420.

[9] Ferris, J. Stephen (1981) A Transactions Theory of Trade Credit Use Quarterly Journal of Economics; 96(2), May, pages 243-70.

[10] Frank, Murray; Maksimovic, Vojislav. (1999) Trade Credit, Collateral, and Adverse Selection Mimeo

[11] Hart, Oliver Firms Contracts and Financial Structure. Clarendon Lectures in Economics. Oxford University Press 1995.

[12] Hart, Oliver; Moore, John (1994) A Theory of Debt Based on the Inalienability of Human Capital Quarterly Journal of Economics; 109(4), November, pages 841-79. 
[13] Hart, Oliver; Moore, John (1998) Default and Renegotiation: A Dynamic Model of Debt Quarterly Journal of Economics; 113(1), February, pages 1-41.

[14] Holmstrőm, Bengt; Tirole: Jean. (1998) Private and Public Supply of Equity Journal of Political Economy Vol 106 (1).

[15] Kiyotaki, Nobuhiro; Moore, John (1990) Credit Cycles Journal of Political Economy; 105(2), April 1997, pages 211-48.

[16] Kreps David M. A Course in Microeconomic Theory Princeton University Press pages $791-815$

[17] Mian, Shehzad L.; Smith, Clifford W., Jr. (1992) Accounts Receivable Management Policy: Theory and Evidence Journal of Finance; 47(1), March, pages 169-200.

[18] Ng, Chee K.; Janet Kiholm Smith, Richard L. Smith. (1999) Evidence on the Determinants of Credit Terms Used in Interfirm Trade Journal of Finance 54(3) June, pages $1109-29$

[19] Nilsen, Jeffrey H. (1994) The Impact of Credit Markets on Monetary Policy Princeton University, $\mathrm{PhD}$.

[20] Nilsen, Jeffrey H. (1999) Trade Credit and the Bank Lending Channel. Studienzentrum Gerzensee discussion paper 99.04

[21] Petersen, Mitchell A.; Rajan, Raghuram G. (1997) Trade Credit: Theories and Evidence Review of Financial Studies; 10(3), Fall, pages 661-91.

[22] Schwartz, Robert A. (1974) An Economic Model of Trade Credit Journal of Financial and Quantitative Analysis. 9(4) September, pages 643-57.

[23] Smith, Janet Kiholm (1987) Trade Credit and Informational Asymmetry Journal of Finance; 42(4), September, pages 863-72.

[24] Smith, Jennifer Inter Enterprise Debt and Monetary Policy in the UK Mimeo, Bank of England; April 1995.

[25] Wilner, Benjamin S (2000) The Exploitation of Relationships in Financial Distress: The Case of Trade Credit Journal of Finance. 
[26] Wilner, Benjamin S (1995) The Use of Trade Credit by American Corporations PhD thesis Northwestern University, 120 pages 


\section{Appendix 1}

\subsection{Proof of Proposition 1}

The customer has two basic strategies when using the startup technology: one is to invest all possible funds in the project, the other one is to invest minimum funds in the project (i.e. almost zero) and only invest all funds when using the mature technology. All other strategies are linear combinations of these two, so if we prove that investing all funds dominates investing almost zero, we will prove that it dominates all other strategies. To prove this we use the unimprovability principle that says that a strategy is optimal if we cannot find a "one-shot" deviation that improves the strategy. ${ }^{39}$ To do so we compare the strategy of investing all possible funds with the "one-shot deviation" strategy of investing minimum funds on the first startup period and then investing all possible funds in any other period (even if the prototype strategy is used again). If this "one-shot deviation" is not an improvement, the unimprovability principle guarantees that deviating in any further period is suboptimal too. The value function of investing an infinitesimal amount for only one period is:

$$
S_{\epsilon}=\frac{\delta}{\beta}(\gamma N+(1-\gamma) S)
$$

We want to show that there exists a value $\delta^{*} \epsilon(0, \beta)$ such as for every $\delta<\delta^{*}$ it is optimal to invest all available funds even when using the prototype technology.

We know that when $\delta=\beta$ then $\frac{S_{\epsilon}}{S}=\frac{(\gamma N+(1-\gamma) S)}{S}>1$

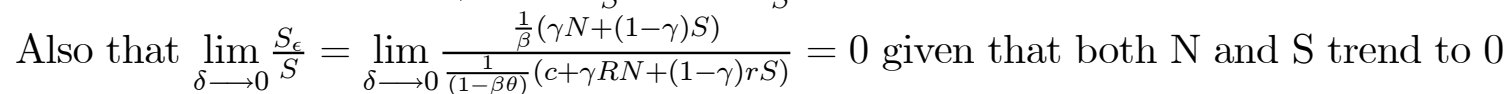
as $\delta$ goes to zero

For any other values of $\delta$ we can evaluate $\frac{S_{\epsilon}}{S}$ using (1) and (15)

$$
\frac{S_{\epsilon}}{S}=\frac{\frac{\delta}{\beta}(\gamma N+(1-\gamma) S)}{S} \text { so } S_{\epsilon}=S \Longrightarrow \delta<\beta \frac{S}{\gamma N+(1-\gamma) S}
$$

Then $\delta^{*}=\beta \frac{S}{S+\gamma(N-S)}$. For $\delta<\delta^{*}$ investing as much as possible in the prototype technology is the optimal strategy. We know that $\frac{S}{S+\gamma(N-S)} \epsilon(0,1)$ given that $N>S$ and that both $N$ and $S$ are positive and increasing in $\delta$, so we can determine that $\delta^{*} \epsilon(0, \beta)$.

Moreover the equilibrium function for $S_{\epsilon}-S=0$ is a continuous quadratic function in $\delta$,so there is a single value for $\delta$ in the interval $(0, \beta)$ such that $\delta^{*}=\beta \frac{S}{S+\gamma(N-S)}$. This is because there are two solutions for $\delta^{*}$ such that $S_{\epsilon}-S=0$ but given that $\frac{S_{\epsilon}}{S}>1$ if $\delta=\beta$ and $\frac{S_{\epsilon}}{S}<1$ if $\delta=0$ then only one of the solutions lies between 0 and $\beta$. This means that there is a unique $\delta^{*} \epsilon(0, \beta)$ so it is also true that if $\delta>\delta^{*}$, investing as little as possible in the startup technology is the optimal strategy.

\subsection{Proof of Proposition 4}

As suppliers make a "take it or leave it" offer, they can choose the optimal level of $p$ up to the point when $M=S$ where customers would opt for their outside option of going

\footnotetext{
${ }^{39}$ See Kreps (1990) for an intuitive explanation of the unimprovability principle.
} 
back to the startup technology. Using the unimprovability principle again we can prove that "one-shot" deviations from this strategy do not pay, by taking the continuation $m$ as given and constant $\bar{m}$ and then taking the derivative of $m$ with respect to $p$ which is $m^{\prime}=\frac{1-\theta-\beta \alpha R \bar{m}+v L}{(-1-p+\theta)^{2}}$. This derivative is positive as long as $\bar{m}<\frac{1-\theta+v L}{\beta \alpha R}$. We know that $\frac{1-\theta+v L}{\beta \alpha R}>1$ and $\bar{m}=\frac{\beta(\alpha-\gamma)(R-r)}{1-\beta \theta-\beta r(\alpha-\gamma)+k R \delta v}<1$ by Assumption 4 so one-shot deviations from setting $p$ at maximum level do not pay. By the unimprovability principle we can now be sure that other deviations are also suboptimal.

\subsection{Proof of the Dominance of "Supplier Insurance" and "Bank Insurance" Over Precautionary Saving}

The relevant value functions for the customer in the matched and first match stage are as follows.

$$
\begin{aligned}
& N_{p}=\frac{1}{(1-d-\beta \theta+L)} \delta[c+(\alpha R+(1-v) L) M+(1-\alpha) r S] \\
& \left.M_{p}=\frac{1}{(1+p-\beta \theta+L)} \delta[c+(\alpha R+(1-v) L) M+(1-\alpha) r S)\right]
\end{aligned}
$$

We use the subscript $\mathrm{p}$ to denote precautionary saving. The value function when searching remains the same. Using precautionary saving is equivalent to paying a premium $L$ at the beginning of the period and getting it back with probability $(1-v)$. This is equivalent in expected terms to paying a premium $v L$ and saving $(1-v) L$ for one period. Bank insurance entails paying $v L$ and no saving. We know from Proposition 1 and Assumption 6 that saving is suboptimal even in the startup stage so it is also suboptimal in the mature stage. Thus bank insurance dominates precautionary saving.

\subsection{Proof of Proposition 5}

The expressions below (marked by the subscript b) show the value functions if the customer decides to use bank insurance.

$$
\begin{aligned}
N_{b} & =\frac{1}{\left(1-d_{b}-\beta \theta+\beta v L\right)} \delta\left(c+\alpha R M_{b}+(1-\alpha) r S_{b}\right) \\
M_{b} & =\frac{1}{\left(1+p_{b}-\beta \theta+\beta v L\right)} \delta\left(c+\alpha R M_{b}+(1-\alpha) r S_{b}\right)
\end{aligned}
$$

The leverage factor of the customers firm has only gone down by $v L$ which is the expected value of the shock. The relevant value functions for the supplier are in the case of bank insurance.

$$
\begin{aligned}
& n_{b}=\frac{1}{\left(1-d_{b}-\beta \theta+\beta v L\right)}\left\{-d_{b}+\beta\left(\alpha R m_{b}+(1-\alpha) r s_{b}\right)\right\} \\
& n_{b}=\frac{1}{\left(1-d_{b}-\beta \theta+\beta v L\right)}\left\{-d_{b}+\beta\left(\alpha R m_{b}+(1-\alpha) r s_{b}\right)\right\}
\end{aligned}
$$

The solutions for $p$ and $d$ for this case, taking into account that $M=S, n=0$ and equations (4) and (1) are:

$$
\begin{aligned}
& d_{b}=\beta \Delta\left((R-r)(\alpha-\gamma)-\frac{\delta}{\beta} v L\right) \\
& p_{b}=\beta \Delta \frac{(i-g)}{(1+g)}\left((R-r)(\alpha-\gamma)-\frac{\delta}{\beta} v L\right)
\end{aligned}
$$

So $d_{b}=d+\beta v L$ and $p_{b}=p-\beta v L$. 


\section{Appendix 2: Sample Structure and Summary Statis- tics}

In Table 1 we report the composition of our sample by year, and firm size, measured both as size in assets and size in terms of number of employees. ${ }^{40}$ We show the number of observations for the different categories. The sample contains up to 5 observations per firm. ${ }^{41}$

Table 1: Sample composition: Number of firms by year and size

\begin{tabular}{|l|r|r|r|r|r|r|r|r|}
\hline Year & 1993 & 1994 & 1995 & 1996 & 1997 & 1998 & 1999 & Total \\
\hline Observations & 1551 & 8681 & 41593 & 48578 & 50799 & 51245 & 43941 & 243338 \\
\hline \% of total sample & 0.63 & 3.52 & 16.88 & 19.72 & 20.62 & 20.80 & 17.83 & 100 \\
\hline
\end{tabular}

\begin{tabular}{|l|r|r|r|r|r|r|r|r|}
\hline Size (Assets-£M) & $<0.1$ & $.1-.25$ & $.25-1$ & $1-5$ & $5-50$ & $50-500$ & $>500$ & Total \\
\hline Observations & 3816 & 10024 & 54126 & 110717 & 56120 & 9597 & 1494 & 246388 \\
\hline \% of total sample & 1.54 & 4.06 & 21.9 & 44.93 & 22.77 & 3.89 & 0.6 & 100 \\
\hline
\end{tabular}

\begin{tabular}{|l|r|r|r|r|r|r|r|r|}
\hline Size (Employees) & $<5$ & $5-50$ & $50-250$ & $250-500$ & $500-5 \mathrm{k}$ & $5 \mathrm{k}-25 \mathrm{k}$ & $>25 \mathrm{k}$ & Total \\
\hline Observations & 7797 & 67319 & 65092 & 11973 & 12168 & 1078 & 289 & 169472 \\
\hline \% of total sample & 4.60 & 39.72 & 38.40 & 7.06 & 7.17 & 0.63 & 0.17 & 100 \\
\hline
\end{tabular}

Considering the distribution of the sample by year, most of the firms are sampled between 1995 and 1999. Data is only available at most for five years per firm. This makes the distribution to concentrate in the last five possible years. With respect to firm size we can see how relatively small firms are represented in the firm. A percentage of $27 \%$ of the firm-observations in the sample have less than $£ 1$ million assets and $44 \%$ of them have less than 50 employees. As the amount of firms represented in the sample is quite high, this leaves us with a good number of small firms. This is particularly important when dealing with empirical evidence regarding trade credit, as trade credit is likely to be more important for small firms that typically have less alternative sources of finance. ${ }^{42}$

In Table 2 we also report the summary statistics for the different variables that we are going to use throughout our empirical analysis. We report the mean and the variance of the different variables, as well as three position measures. The sample median, the value for the $10 \%$ quantile and $90 \%$ quantile. These values can be used to evaluate the quantitative importance of the different results in our regressions. ${ }^{43}$

\footnotetext{
${ }^{40}$ Assets for Table 1 are reported in £ Million.

${ }^{41}$ For most firms (75\%) we have the last 5 observations available (eg. 1995-1999, 1994-1998 etc) others have less than 5 observations. The average observations per firm is 4.4 .

${ }^{42}$ The proportion of big firms in our sample is much higher than the one in the country as a whole. However, given that the regressions of this chapter constitute a conditional analysis, the fact that we have a stratified sample should not bias our results. The stratified nature of the sample, should only be a problem if we wanted to do a descriptive analysis of variables like: the average firm size or the average use of trade credit When reporting these statistics, one has to be aware that the fact that big firms are oversampled in our dataset makes these descriptive statistics biased, so they are not representative of the UK economy as a whole.

${ }^{43}$ Some of the variables used in our estimations are ratios over the level of assets of the firm. This means that we may get some extreme results when the assets of the firm are close to zero. Calculating the summary statistics of the following ratios: trade credit over assets, trade credit growth rate, trade credit over sales; we have excluded from the calculation the top (bottom) $1 \%$ of the observations, to avoid unusually high values when the denominator of these ratios is too close to zero. We also drop these observations in further estimations whenever one of these ratios appears in the regression.
} 
Table 2: Summary statistics

\begin{tabular}{|l|r|r|r|r|r|}
\hline Variable & mean & \multicolumn{1}{|c|}{ Std. dev. } & median & 10\% qt. & 90\% qt. \\
\hline Assets & 22270 & 343074 & 2081 & 365 & 18683 \\
\hline Employees & 329 & 2965 & 59 & 9 & 394 \\
\hline Trade credit & 2500 & 29826 & 263 & 0 & 2874 \\
\hline Trade credit/Assets & 0.18 & 0.18 & 0.13 & 0 & 0.44 \\
\hline Trade credit/Sales & 0.10 & 0.12 & 0.08 & 0 & 0.21 \\
\hline Trade credit growth rate & 0.13 & 0.71 & 0.02 & -0.54 & 0.85 \\
\hline Trade credit/Total debt & 0.43 & 0.32 & 0.41 & 0 & 0.94 \\
\hline Inventories & 3483 & 37935 & 318 & 0 & 3618 \\
\hline Inventories/Assets & 0.21 & 0.19 & 0.17 & 0 & 0.48 \\
\hline Short-term bank loans & 4147 & 68126 & 200 & 0 & 3555 \\
\hline St banks/Total Liabilities & 0.26 & 0.27 & 0.18 & 0 & 0.66 \\
\hline Long-term bank loans & 5 & 2944 & 58111 & 0 & 0.35 \\
\hline Lt banks/Total Liabilities & 0.10 & 0.17 & 0.005 & 0 & 0.35 \\
\hline Inventories/Assets & 0.21 & 0.19 & 0.17 & 0 & 0.48 \\
\hline Liquid assets & 1412 & 28944 & 44 & 0 & 1245 \\
\hline Liquid assets/Assets & 0.9 & 0.15 & 0.2 & 0 & 0.30 \\
\hline Age (Years) & 23 & - & 17 & 4.6 & $>100$ \\
\hline Asset Growth Rates & 0.05 & 0.28 & 0.06 & -0.20 & 0.33 \\
\hline Collateral & 6640 & 138308 & 337 & 7 & 10904 \\
\hline Collateral/Assets & 0.23 & 0.21 & 0.18 & 0.007 & 0.54 \\
\hline Profits before tax & 2435 & 42567 & 149 & -64 & 1927 \\
\hline Return on assets & 0.09 & 0.24 & 0.07 & -0.03 & 0.24 \\
\hline Return on equity & 0.16 & 11.8 & 0.25 & -0.09 & 1.21 \\
\hline Monetary variables in thousand pounds. & \multicolumn{5}{|l|}{} \\
\hline
\end{tabular}

We can see in the last two tables that the size distribution of our sample is skewed towards smaller firms. Most of the variables related to the size of the firm such as assets or level of trade credit have average levels higher than the median. This is a characteristic of the population of firms in the UK rather than a special property of our sample, that contains all the big UK firms and only a subsample of the small ones. This points out that our sample is composed mainly by a big group of small and medium firms, but also that all the biggest firms of the UK are also included in the sample. More than half of the firms in our sample have less than 60 employees, while there is almost $10 \%$ of the firms in the sample with more than 300 employees.

With respect to trade credit, the average level of trade credit over assets is $18 \%$ although the variability of this ratio is quite high, as going from the 10th percentile to the 90th percentile means moving from zero trade credit to a $44 \%$ of trade credit over assets. When we measure trade credit as a proportion of sales, the average level falls to $10 \%$, with decile values of zero and $21 \%$. This shows that sales are normally bigger than assets on a per firm basis, but also the fact that not all the firms in our sample report a figure for sales, being the smallest firms the ones for which we have less information about their sales and their profit and loss statement. As a guide for this lack of information about sales, while we have 243338 observations for asset levels, we only have 109387 observations regarding sales. The average size of the firms that report sales in term is $£ 36701 \mathrm{k}$ of assets while for the ones that do not report a sales figure, the average level of assets is $£ 18536$.

The median age of the firms in our sample is 17 years, with firms of all ages represented, including more than $10 \%$ of the sample being firms with more than 100 years of age. If we wanted to do regressions concerning the age of the firm for all firms, this 
would pose a problem, as a firm of more than 100 years of age may have suffered several restructurings, and therefore be "re-born" in some sense after foundation. This is not going to be a problem in our regressions that relate trade credit to firm age as we are only interested in the youngest firms of our sample. In particular, the regressions that use firm age as a dependent variable will concentrate on a subsample of firms of less than 20 years of age. This subsample of observations of firms below 20 years of age contains 34440 firms and 137907 observations. 


\section{Appendix 3: Trade Credit of a Steady Growing Firm}

Typical trade credit contracts may not actually look like a perpetuity. The customer orders some goods and pays for them after some time. However, if we take all the cash flows of an ongoing commercial relationship financed by trade credit it looks similar to a perpetuity contract.

For example, suppose a customer firm starts with a level of input purchases of 100 units and finances $75 \%$ of those via trade credit. The firm sales and input needs grow at a $10 \%$ and the implicit interest rate on trade credit is $35 \%$.

In the first period, the firm gets 75 units of goods from the supplier and pays nothing, so the customer is getting the value of 75 units from the supplier. In the second period, the customer has to pay 101.25 units $(75 * 1.35)$ to the supplier, as capital and interests of the first delivery, but the customer also receives 82.5 new input units to be used in this second period (corresponding to $75 \%$ of 110 units needed). In net terms the customer is effectively paying 18.75 units to the supplier and paying cash for the new deliveries.

The process continues as in Figure 9.

Figure 9

Trade Credit of a steady growing firm.

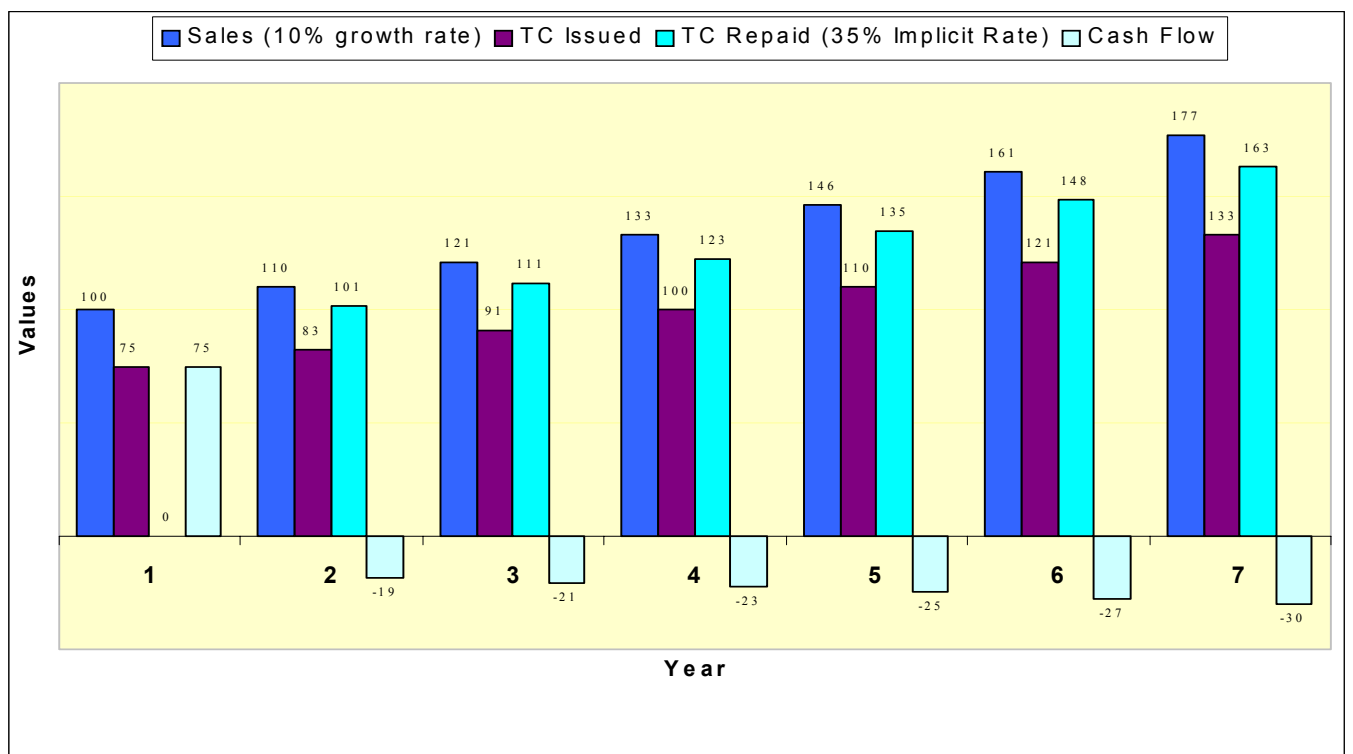

Here trade credit looks like a perpetuity with an initial payment of 75 units, and a first coupon of 18.75 that grows at a $10 \%$ rate. Moreover, if we call $d$ the capital payment and $\left(1+g_{1}\right) p$ the first payment, the relationship $\left(1+g_{1}\right) p=d(1+\rho)-\left(1+g_{1}\right) d$ holds and implies equation (12). 


\section{Appendix 4 Tables and Figures}

Figure 1: Simulated trade credit/assets vs age of the firm

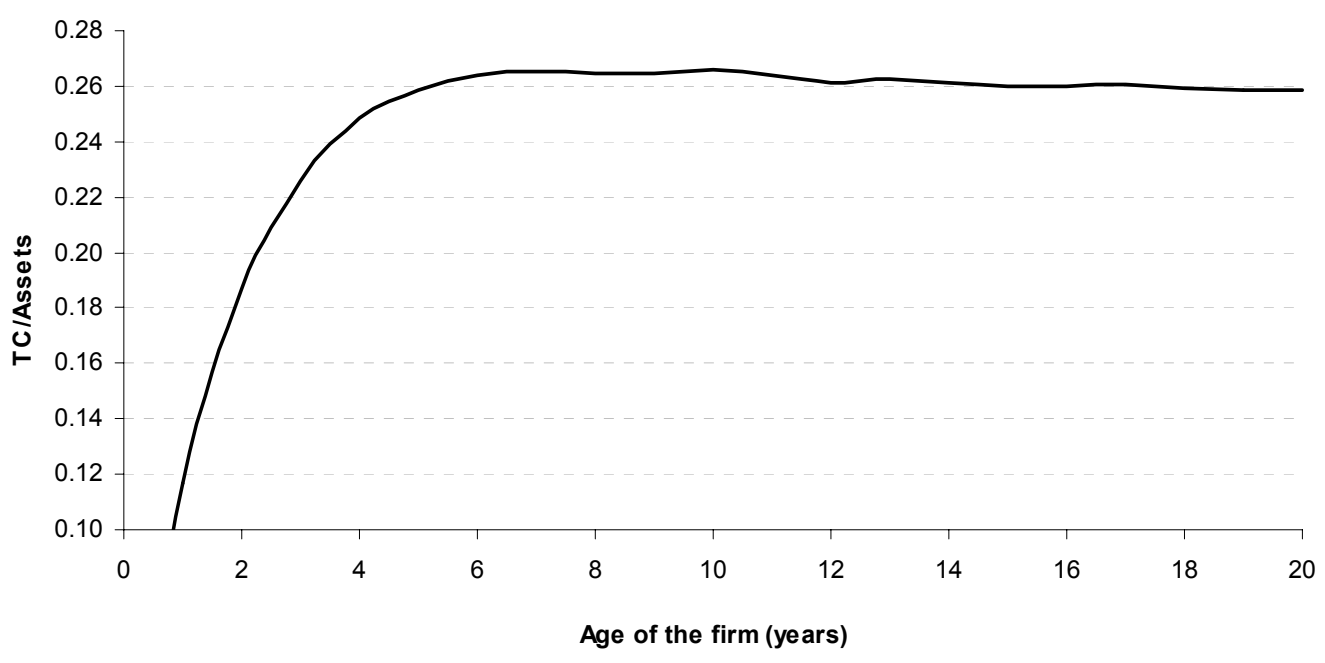

Figure 2: Trade credit/assets vs age of the firm

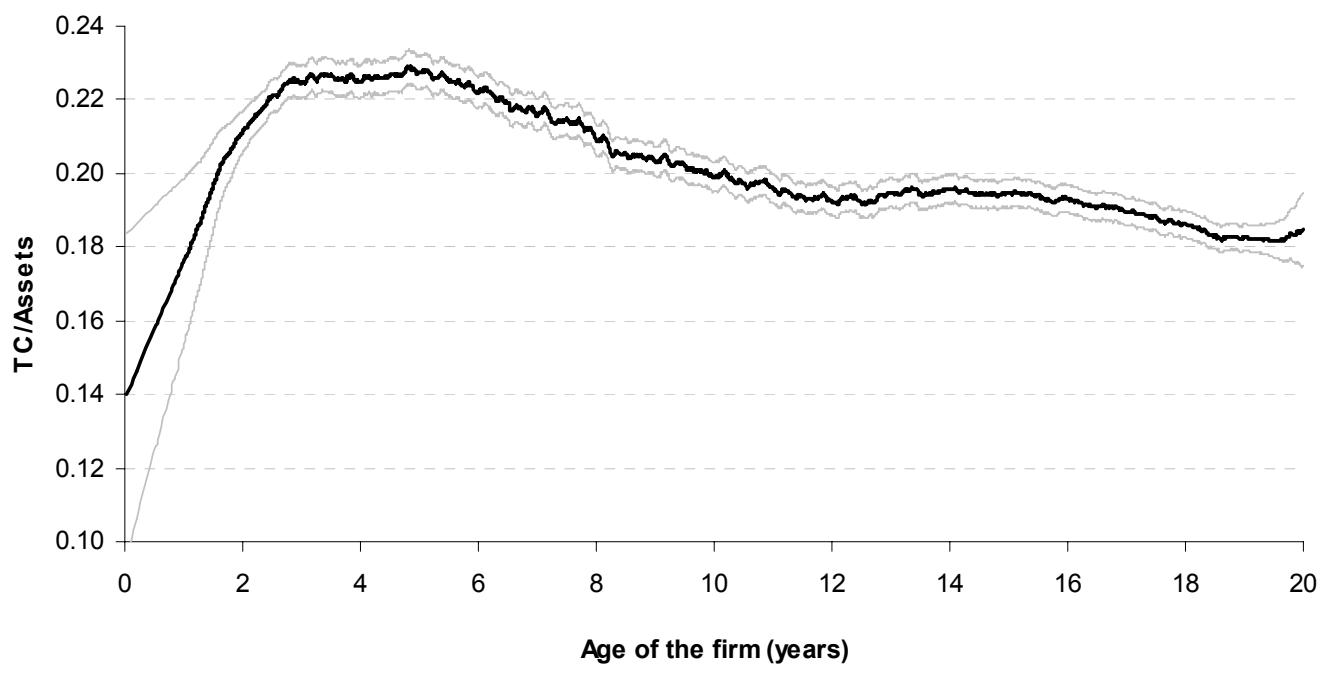

(95\% confidence interval) 
Figure 3: Trade credit/assets vs age of the firm (Spline)

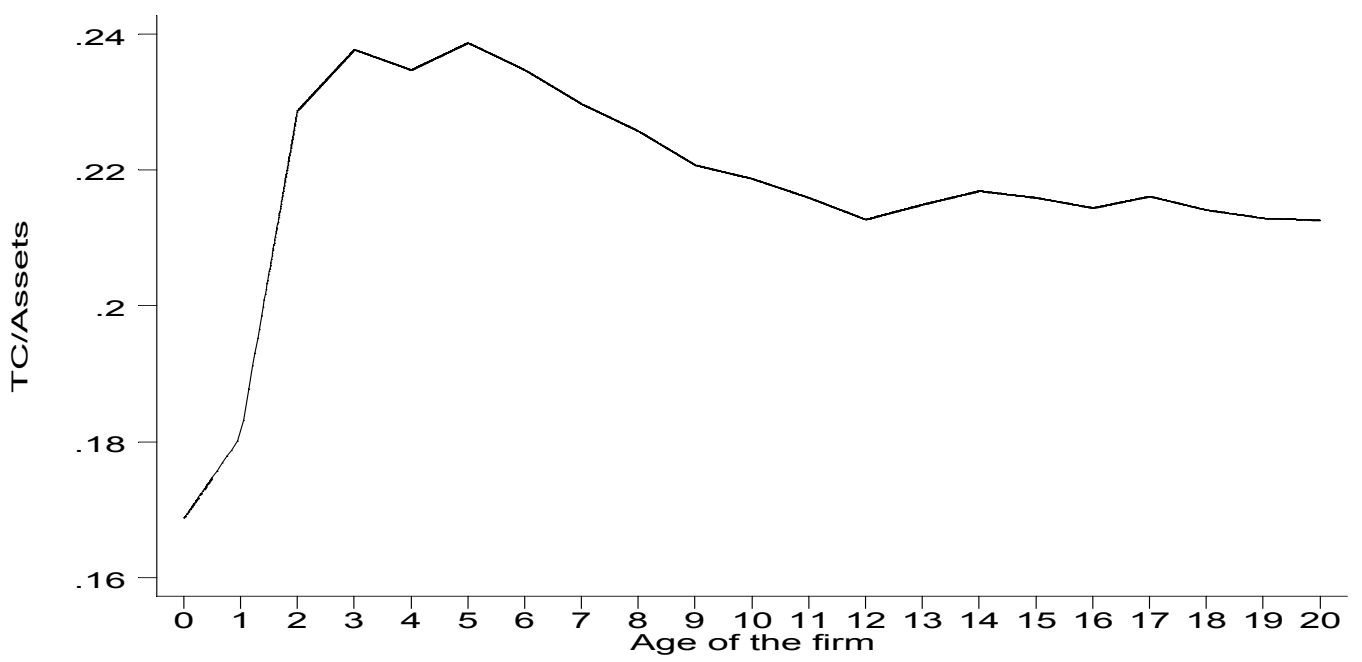

Figure 4: Trade credit/assets vs growth rate of the firm

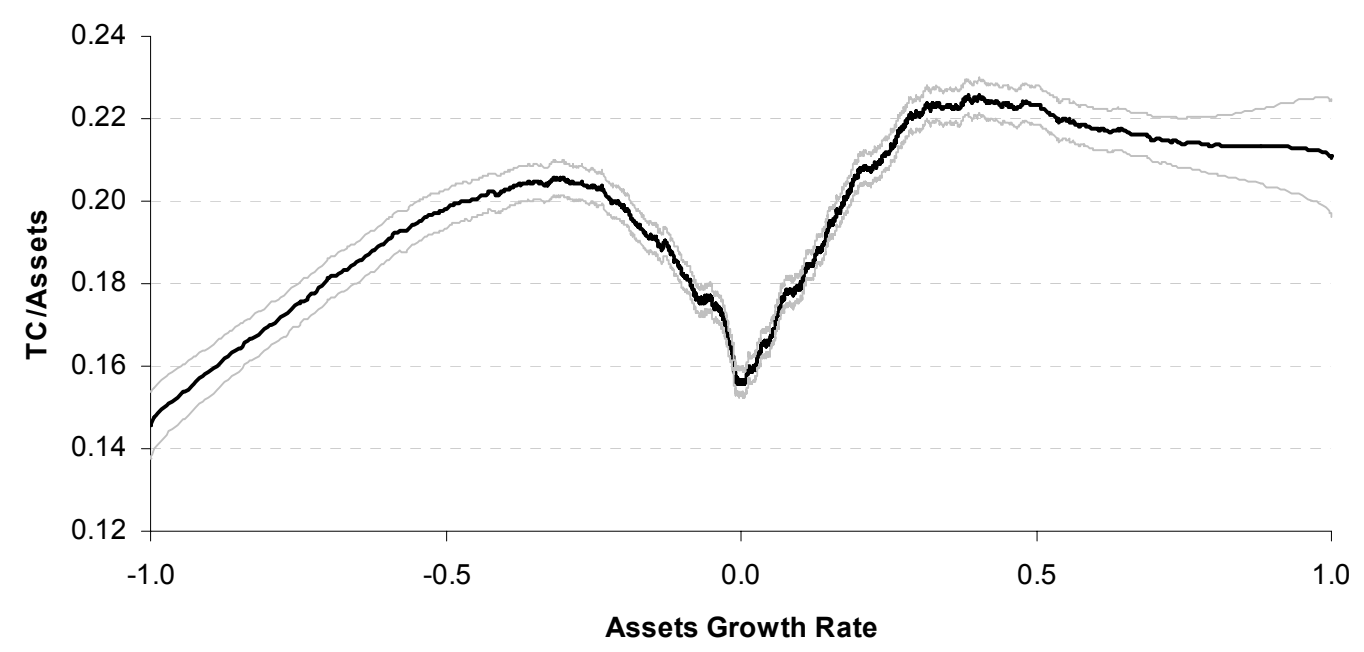

(95\% confidence interval) 
Figure 5: Trade credit/assets vs asset growth rate (Spline)

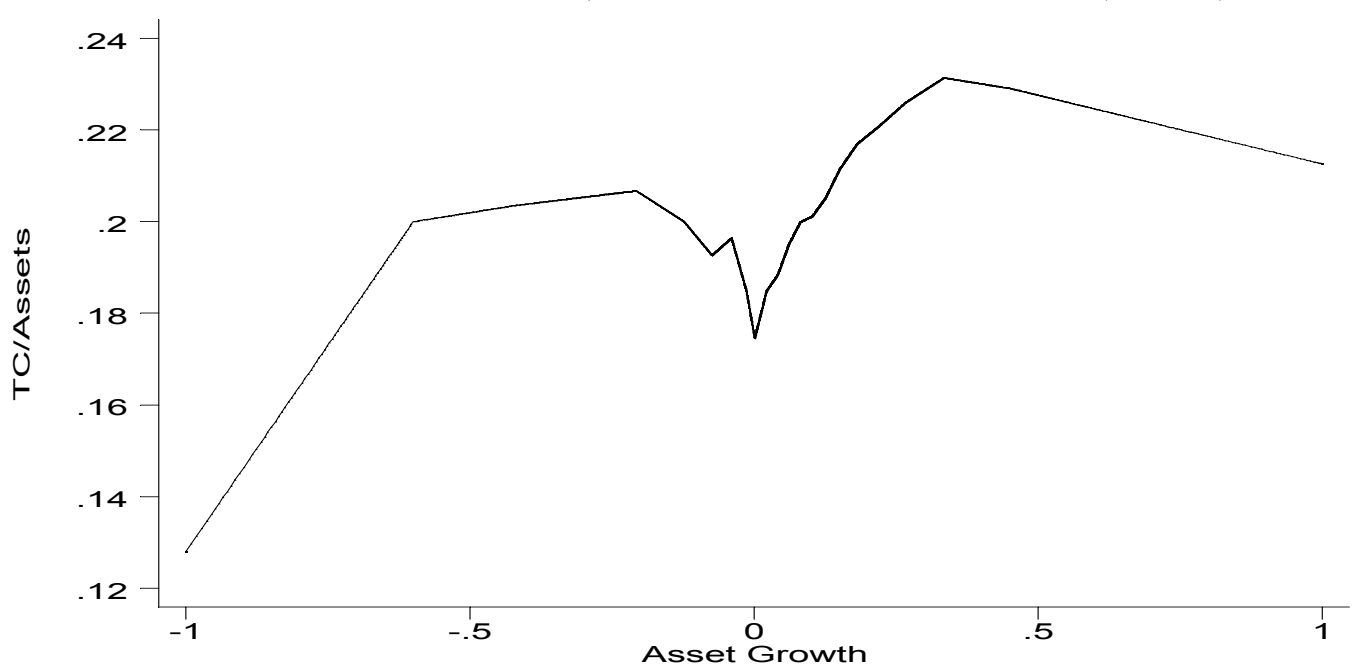

Table 3: Collateral and Liquidity

Panel Data Regressions

\begin{tabular}{|c|c|c|c|c|c|c|}
\hline \multirow[t]{2}{*}{ Dependent Variable: } & \multicolumn{3}{|c|}{ Trade Credit/Total Debt } & \multicolumn{3}{|c|}{ Trade Credit/Assets } \\
\hline & 1 & 2 & 3 & 4 & 5 & 6 \\
\hline (T. C./Tot. Debt $)_{t-1}$ & - & - & $\begin{array}{l}0.458^{*} \\
(51.31)\end{array}$ & - & - & - \\
\hline (T. C./Assets $)_{t-1}$ & - & - & - & - & - & $\begin{array}{l}0.489^{*} \\
(63.67) \\
\end{array}$ \\
\hline Size & $\begin{array}{l}0.0057^{*} \\
(3.21) \\
\end{array}$ & $\begin{array}{l}0.004 \\
(2.41)\end{array}$ & $\begin{array}{l}-0.015^{*} \\
(-6.48) \\
\end{array}$ & $\begin{array}{l}0.021^{*} \\
(25.55) \\
\end{array}$ & $\begin{array}{l}0.020^{*} \\
(26.32)\end{array}$ & $\begin{array}{l}0.021^{*} \\
(19.1)\end{array}$ \\
\hline Inventories & $\begin{array}{l}0.250^{*} \\
(26.42) \\
\end{array}$ & $\begin{array}{l}0.251^{*} \\
(27.51) \\
\end{array}$ & $\begin{array}{l}0.232^{*} \\
(18.86) \\
\end{array}$ & $\begin{array}{l}0.196^{*} \\
(39.74) \\
\end{array}$ & $\begin{array}{l}0.196^{*} \\
(41.66) \\
\end{array}$ & $\begin{array}{l}0.178^{*} \\
(26.93) \\
\end{array}$ \\
\hline Collateral & $\begin{array}{c}-0.098^{*} \\
(-11.12) \\
\end{array}$ & $\begin{array}{c}-0.092^{*} \\
(-11.10) \\
\end{array}$ & $\begin{array}{l}-0.120^{*} \\
(-10.22) \\
\end{array}$ & $\begin{array}{l}-0.006 \\
(-1.41) \\
\end{array}$ & $\begin{array}{l}-0.009 \\
(-0.22)\end{array}$ & $\begin{array}{c}-0.021^{*} \\
(-3.53)\end{array}$ \\
\hline Liquid Assets & $\begin{array}{l}0.141^{*} \\
(18.60)\end{array}$ & $\begin{array}{l}0.147^{*} \\
(20.29)\end{array}$ & $\begin{array}{l}0.086^{*} \\
(8.82)\end{array}$ & $\begin{array}{l}-0.020^{*} \\
(-5.25)\end{array}$ & $\begin{array}{l}-0.018^{*} \\
(-5.07)\end{array}$ & $\begin{array}{c}-0.031^{*} \\
(-6.01)\end{array}$ \\
\hline Sector time trends & No & Yes & No & No & Yes & No \\
\hline
\end{tabular}

All regresions include as control variables:firm fixed effects, year dummies, asset growth rates and age.(not reported).

Columns 3 and 6 use the GMM Arellano-Bond estimation procedure

GMM estimator uses first differences and inclues up to 3 lags as instrumental variables

t-statistic in parenthesis (z-statistic for GMM)

$*$ indicates significant at $99 \%$

Size: Log. of total assets; Inventories: Finished and work in progress stocks/total assets;

Collateral: Fixed assets / total assets; Liquid assets: Cash and liquid deposits 